\title{
Design and Implementation of an Underwater Sound Recording Device
}

\author{
JJ Martinez \\ Z Deng \\ JR Myers \\ JS Rohrer \\ TJ Carlson \\ KA Caviggia
}

September 2011

\section{Pacific Northwest}

NATIONAL LABORATORY

Proudly Operated by Battelle Since 1965 


\title{
DISCLAIMER
}

This report was prepared as an account of work sponsored by an agency of the United States Government. Neither the United States Government nor any agency thereof, nor Battelle Memorial Institute, nor any of their employees, makes any warranty, express or implied, or assumes any legal liability or responsibility for the accuracy, completeness, or usefulness of any information, apparatus, product, or process disclosed, or represents that its use would not infringe privately owned rights. Reference herein to any specific commercial product, process, or service by trade name, trademark, manufacturer, or otherwise does not necessarily constitute or imply its endorsement, recommendation, or favoring by the United States Government or any agency thereof, or Battelle Memorial Institute. The views and opinions of authors expressed herein do not necessarily state or reflect those of the United States Government or any agency thereof.

\author{
PACIFIC NORTHWEST NATIONAL LABORATORY \\ operated by \\ BATTELLE \\ for the \\ UNITED STATES DEPARTMENT OF ENERGY \\ under Contract DE-AC05-76RL01830
}

Printed in the United States of America

$$
\begin{aligned}
& \text { Available to DOE and DOE contractors from the } \\
& \text { Office of Scientific and Technical Information, } \\
& \text { P.O. Box } 62 \text {, Oak Ridge, TN } 37831-0062 \text {; } \\
& \text { ph: }(865) 576-8401 \\
& \text { fax: (865) 576-5728 } \\
& \text { email: reports@adonis.osti.gov }
\end{aligned}
$$

Available to the public from the National Technical Information Service 5301 Shawnee Rd., Alexandria, VA 22312 ph: (800) 553-NTIS (6847)

email: orders $a$ ntis.gov $<$ http://www.ntis.gov/about/form.aspx $>$ Online ordering: http://www.ntis.gov 


\section{Design and Implementation of an Underwater Sound Recording Device}

$\begin{array}{ll}\text { JJ Martinez } & \text { Z Deng } \\ \text { JR Myers } & \text { JS Rohrer } \\ \text { TJ Carlson } & \text { KA Caviggia }\end{array}$

September 2011

Prepared for

the U.S. Department of Energy

under Contract DE-AC05-76RL01830

Pacific Northwest National Laboratory

Richland, Washington 99352 



\section{Preface}

This project was conducted by the Pacific Northwest National Laboratory for the U.S. Department of Energy Office of Energy Efficiency \& Renewable Energy, Wind \& Water Power Program. To measure underwater acoustic signals in a field environment, a compact device that can be connected to multiple hydrophones or other underwater sound sensors was needed. To accomplish this, a device called the Underwater Sound Recorder (USR), which allows up to $1 \mathrm{~h}$ and $55 \mathrm{~min}$ of data to be collected from two sensors simultaneously, was designed, built, and tested. The USR filters out frequency components above $15 \mathrm{kHz}$ and allows the total system a user-selectable gain of $30 \mathrm{~dB}, 36 \mathrm{~dB}, 44 \mathrm{~dB}$, or $50 \mathrm{~dB}$. Benchtop laboratory testing verified that the device operates as designed. Simulated field testing performed in a large water tank using a hydrophone and a high-power underwater transducer demonstrated that the USR performs as well as larger commercially available data acquisition systems, which are not suited for field use. 



\section{Summary}

At the request of the U.S. Department of Energy Wind \& Water Power Program, researchers and engineers at Pacific Northwest National Laboratory designed the Underwater Sound Recorder (USR), a deployable system to record underwater acoustic signals using two hydrophones or other sound/pressure sensors. Two versions of the USR were created; one is submersible to a maximum depth of $300 \mathrm{~m}$, and the other, although watertight, is not intended to be fully submersed. The USR design is composed of three custom circuit boards and a Sony PCM-D50 data recorder. One of the circuit boards converts the voltage from four size $\mathrm{D}$ alkaline or nickel-metal hydride batteries to $\pm 12 \mathrm{~V}$. The second circuit board displays the current battery voltage on a small liquid crystal display screen. The third circuit board processes the analog signal by filtering out frequency components above $15 \mathrm{kHz}$ and allows the total system a user-selectable gain of $30 \mathrm{~dB}, 36 \mathrm{~dB}, 44 \mathrm{~dB}$, and $50 \mathrm{~dB}$. The PCM-D50 data recorder has a 24bit resolution, $96-\mathrm{kHz}$ sampling rate, and 4 gigabytes of built-in memory, sufficient to record up to approximately $1 \mathrm{~h}$ and $55 \mathrm{~min}$ of data from two channels.

To verify the design of the USR, tests were performed on the hydrophone signal processing board, the PCM-D50 data recorder, and the complete system for the four different USRs that were built. The tests were divided into two categories - benchtop tests and in-water tank tests. The benchtop tests involved using a National Instruments data acquisition system to send sinusoidal voltages with frequencies varying between $100 \mathrm{~Hz}$ and $50 \mathrm{kHz}$ directly to each component being tested and recording the output. At each frequency, the root mean square voltage of the recorded signal and the input signal were used to calculate the gain for that frequency. These tests were repeated for each gain setting and channel.

For the tank tests, a high-power underwater transducer was used to transmit two different underwater acoustic signals to a hydrophone in a large elongated oval tank. The different signals used were recordings of an underwater explosion and a whale call. The signal received by the hydrophone was recorded by each channel of the USR at each gain setting. The signals also were recorded by the same National Instruments data acquisition system used for the benchtop testing. The signals recorded by both the USR and the data acquisition system were converted to physical units, using the measured gain values and the hydrophone sensitivity, and the spectra were calculated by taking a fast Fourier transform of the data. The peak pressures from the spectra were used to compare the results from the USR against the National Instruments data acquisition system.

The results from the benchtop testing showed that the actual gain values of the hydrophone signal processing boards were very close to the designed gain values. On average, the gain values were only $0.35 \mathrm{~dB}$ higher than the designed values. Comparing between the different hydrophone signal processing boards, the results were very similar, with a standard deviation of only $0.02 \mathrm{~dB}$. The cutoff frequency for the low-pass filter incorporated into the hydrophone signal processing board also was found to be close to the designed value. For the PCM-D50, the gain between the different channels of each of the units tested was found to be slightly more variable than the hydrophone signal processing board, with a standard deviation of $0.25 \mathrm{~dB}$. The gain values measured from the complete USR systems were in very close agreement to the values calculated by summing the results from the individual component tests. The difference between the actual system gains and the gains calculated from the individual components was only $0.02 \%$. 
The results from the tank testing verified that the USR was able to obtain peak pressures in the frequency domain that were very similar to the peak pressures obtained by the National Instruments data acquisition system used. The measurements of the whale call were found to agree more closely than the measurements of the underwater explosion, which could be a result of the fact that the bandwidth of the whale call is much narrower than that of the underwater explosion. The average percentage difference of the whale call measurements was $1.4 \%$; for the underwater explosion, the average percentage difference was $3.0 \%$.

With the USR, field measurements of underwater acoustic signals can be easily obtained using a compact, portable, and watertight device. The submersible version is well suited for measurements where the ability to record long measurements at depths would require very long hydrophone cables or extension cables that can introduce additional noise to the recorded waveform. The nonsubmersible version is more appropriate for measurements that have a relatively short duration and known start and end times because the nonsubmersible version can use the remote and USB connector to easily start recording, stop recording, and extract the collected data.

The submersible version of the USR can be deployed with two hydrophones to a depth of $300 \mathrm{~m}$ and allowed to collect data for slightly less than $2 \mathrm{~h}$ before the device is retrieved and the data are extracted. These features would allow the submersible version of the USR to be deployed to record any sounds generated by objects such as vessels or the vocalizations of some marine mammals that can occur sporadically during the recording period. The nonsubmersible version of the USR would be more appropriate for recoding underwater activities, such as monitoring pressures generated by underwater explosions or pile driving, where several events occur at predefined times. Because waveforms that contain only the signals of interest are recorded, the time required to post-process the collected data can be significantly reduced. 


\section{Acknowledgments}

This project was supported by the U.S. Department of Energy's Office of Energy Efficiency and Renewable Energy Wind \& Water Power Program. The authors are grateful for the contributions and input of many Pacific Northwest National Laboratory staff, including Jeff Ward, Mark Weiland, Christa Woodley, Michele Halverson, Huiying Ren, Kevin Gervais, and Vinh Nguye. Andrea Currie was the technical editor for this document. 



\section{Acronyms and Abbreviations}

$\begin{array}{ll}\text { BNC } & \text { Bayonet Neill-Concelman } \\ \mathrm{dB} & \text { decibel(s) } \\ \mathrm{GB} & \text { gigabyte(s) } \\ \mathrm{h} & \text { hour(s) } \\ \text { in. } & \text { inch(es) } \\ \mathrm{kg} & \text { kilogram(s) } \\ \mathrm{kHz} & \text { kilohertz } \\ \mathrm{m} & \text { meter(s) } \\ \mathrm{MHz} & \text { megahertz } \\ \text { min } & \text { minute(s) } \\ \mathrm{mV} & \text { millivolt(s) } \\ \mathrm{NI} & \text { National Instruments } \\ \mathrm{NiMH} & \text { nickel-metal hydride } \\ \mathrm{Pa} & \text { pascal(s) } \\ \text { PC } & \text { personal computer } \\ \text { PNNL } & \text { Pacific Northwest National Laboratory } \\ \mathrm{s} & \text { second(s) } \\ \text { USB } & \text { universal serial bus } \\ \text { USR } & \text { Underwater Sound Recorder } \\ \text { V } & \text { volt(s) } \\ \text { WAV } & \text { waveform audio file } \\ & \end{array}$





\section{Contents}

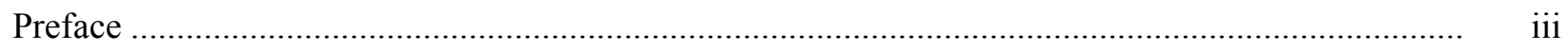

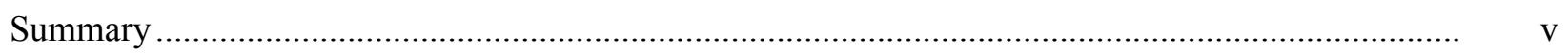

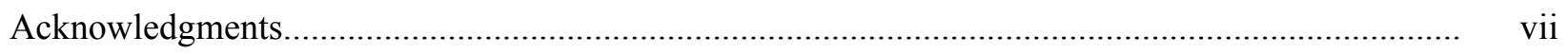

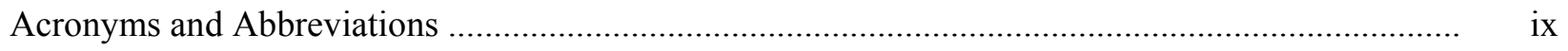

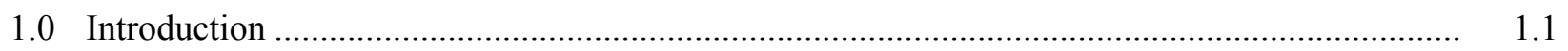

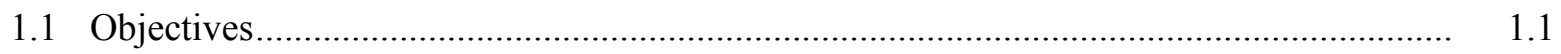

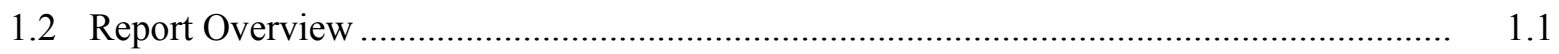

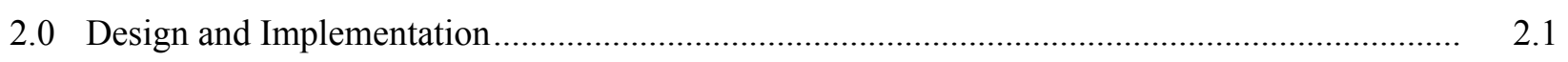

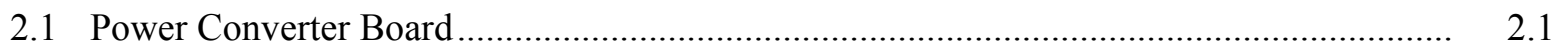

2.2 Battery Voltage Monitor .......................................................................................... 2.1

2.3 Hydrophone Signal Processing Board........................................................................... 2.2

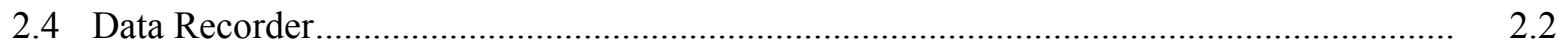

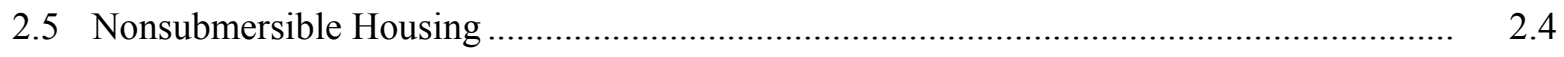

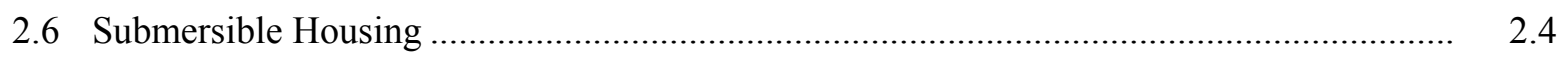

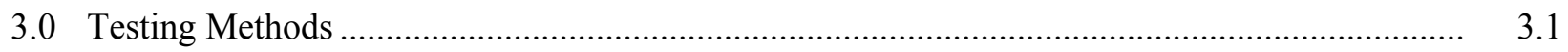

3.1 Hydrophone Signal Processing Board..................................................................... 3.1

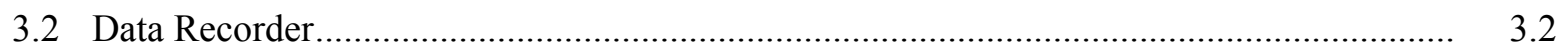

3.3 Complete Underwater Sound Recorder System ......................................................... 3.2

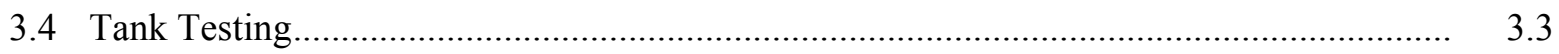

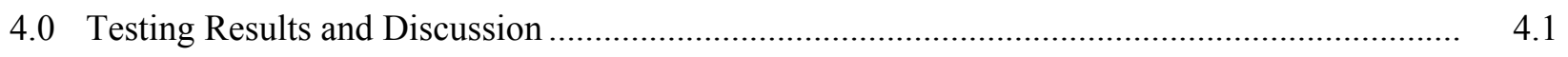

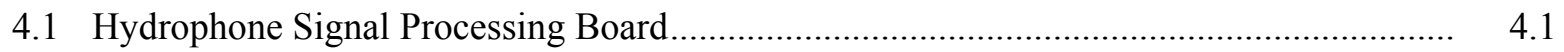

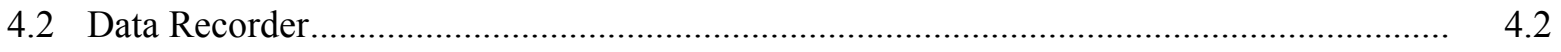

4.3 Complete Underwater Sound Recorder System .......................................................... 4.3

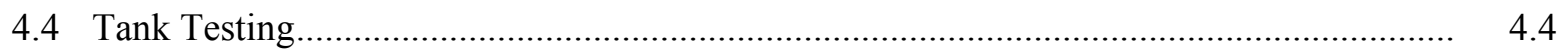

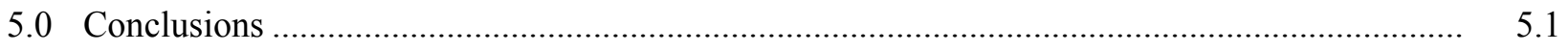

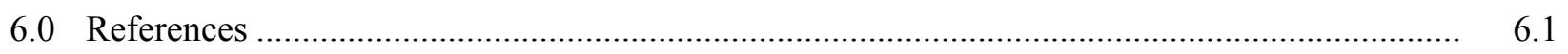

Appendix A - Schematics.......................................................................................... A.1

Appendix B - Test Component Frequency Response................................................................. B.1

Appendix C - Underwater Sound Recorder Users Guide .......................................................... C.1

Appendix D - Performance Testing Results ...................................................................... D. 


\section{Figures}

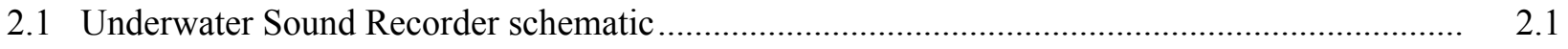

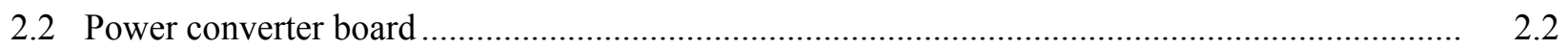

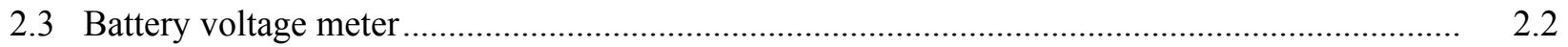

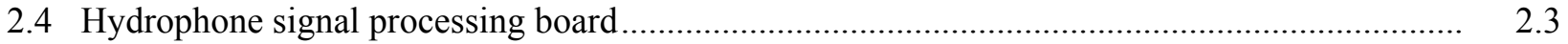

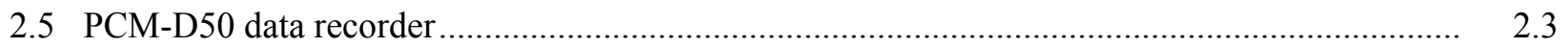

2.6 Nonsubmersible version of the Underwater Sound Recorder..................................................... 2.4

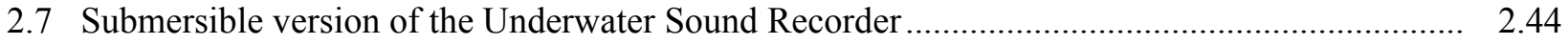

3.1 Hydrophone signal processing board test schematic ......................................................... 3.2

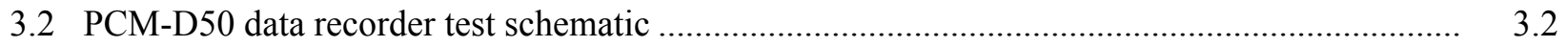

3.3 Underwater Sound Recorder test schematic ...................................................................... 3.3

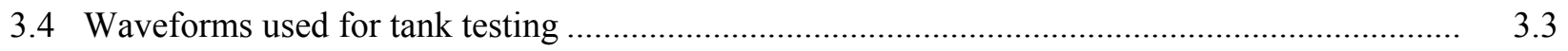

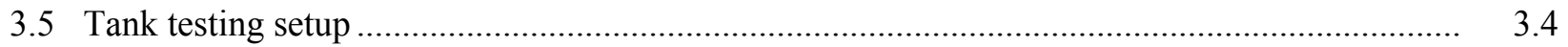

3.6 Tank testing schematic for Underwater Sound Recorder ..................................................... 3.5

3.7 Schematic for testing the acquisition performance of the National Instruments PXIe-6124

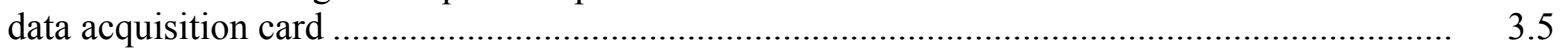

4.1 Average hydrophone signal processing board frequency response for each gain setting ............ 4.1

4.2 PCM-D50 data recorder frequency response for each channel of each unit tested..................... 4.2

4.3 Underwater Sound Recorder system average frequency response for each gain setting ............. 4.3

4.4 Sample spectrum comparisons from the tank testing........................................................... 4.5

\section{Tables}

4.1 Hydrophone signal processing board average and standard deviation of the gain at $100 \mathrm{~Hz}$ for each gain setting.

4.2 PCM-D50 data recorder gain at $100 \mathrm{~Hz}$ for each channel of each unit tested.

4.3 Underwater Sound Recorder system average and standard deviation of the gain at $100 \mathrm{~Hz}$ for each gain setting

4.4 Comparison between gain from complete Underwater Sound Recorder system test and the sum of the results from the hydrophone signal processing board and the PCM-D50 data recorder tests

4.5 Percentage difference between the results from the PXIe-6124 measurements and the Underwater Sound Recorder measurements for the whale call waveform

4.6 Percentage difference between the results from the PXIe-6124 measurements and the Underwater Sound Recorder measurements for the underwater explosion waveform 


\subsection{Introduction}

Many underwater processes such as underwater explosions or pile driving have the potential to create large pressure waves that could possibly harm fish or other aquatic life (Teleki and Chamberlain 1978; Wiley et al. 1981; Govoni et al. 2003, 2008; Popper et al. 2004, 2006; Carlson et al. 2007 ${ }^{1}$ ). Hydrophones can be used to measure dynamic pressure changes but typically output relatively low voltages, so the signals often must be amplified prior to measuring. To monitor potentially harmful underwater processes, a portable, watertight, and easy-to-use device that can be connected to multiple hydrophones is needed. The device should have an amplifier that allows the gain to be varied to allow for measuring underwater acoustic signals with a wide range of sound pressure levels. The same device could be used also for other activities such as recording sounds generated by vessels or the vocalizations of some marine mammals.

The purpose of this project was to design, build, and test an underwater sound recording device for the U.S. Department of Energy Wind \& Water Power Program. The device designed by researchers and engineers at Pacific Northwest National Laboratory (PNNL) is referred to as the Underwater Sound Recorder (USR), which can be connected to one or two hydrophones or other underwater sound sensors. The USR contains a 26-dB preamplifier and a user-selectable gain that permits additional amplification of the input to the system at four different levels: $0 \mathrm{~dB}, 6 \mathrm{~dB}, 14 \mathrm{~dB}$, and $20 \mathrm{~dB}$. The device used for storing the filtered waveforms also supplies approximately $4 \mathrm{~dB}$ of gain. Signals within the frequency range from $20 \mathrm{~Hz}$ to $15 \mathrm{kHz}$ may be recorded using the USR. Two versions of the USR were created-a submersible and a nonsubmersible version.

\subsection{Objectives}

The objectives of this project were

- to design and build a portable, watertight, and easy-to-use device to record underwater acoustic signals from two hydrophones or other underwater sound sensors

- to test the components from each of the USRs that were built to ensure that they operate as designed

- to test each of the devices built to record simulated signals representative of typical signals that could be measured in the field using a hydrophone connected to the USR.

\subsection{Report Overview}

Section 2 describes the design of the components of the USR and how the components were implemented into making a complete system. Section 3 presents the methods used for testing the performance of the USR, followed by the results and discussion in Section 4. Conclusions are given in Section 5, followed by the sources cited in this report in Section 6.

\footnotetext{
${ }^{1}$ Memorandum from Thomas Carlson (PNNL), Mardi Hastings (Penn State University), and Arthur Popper (University of Maryland) to Suzanne Theiss (California Department of Transportation) and Paul Wagner (Washington State Department of Transportation), "Update on Recommendations for Revised Interim Sound Exposure Criteria for Fish During Pile Driving Activities,” December 21, 2007, Richland, Washington.
} 
Appendix A displays the electrical schematics for each of the components designed, as well as a detailed schematic depicting the connections between each of the components of the USR. Appendix B presents the frequency response curves for the components used in the testing of the USRs. Appendix C contains the user's guide for the USR. Results for each of the USRs tested are given in Appendix D. 


\subsection{Design and Implementation}

The USR consists of four size D batteries, a battery voltage monitor, power converter board, sensor signal processing board, digital data recorder, watertight housing, two waterproof connectors for sensors, one waterproof connecter for a wired remote control module, and a fourth waterproof connector for enabling power (Figure 2.1). Two different types of housing are available — one for normal uses (nonsubmersible) and another designed to be completely submersed in water up to a depth of $300 \mathrm{~m}$.

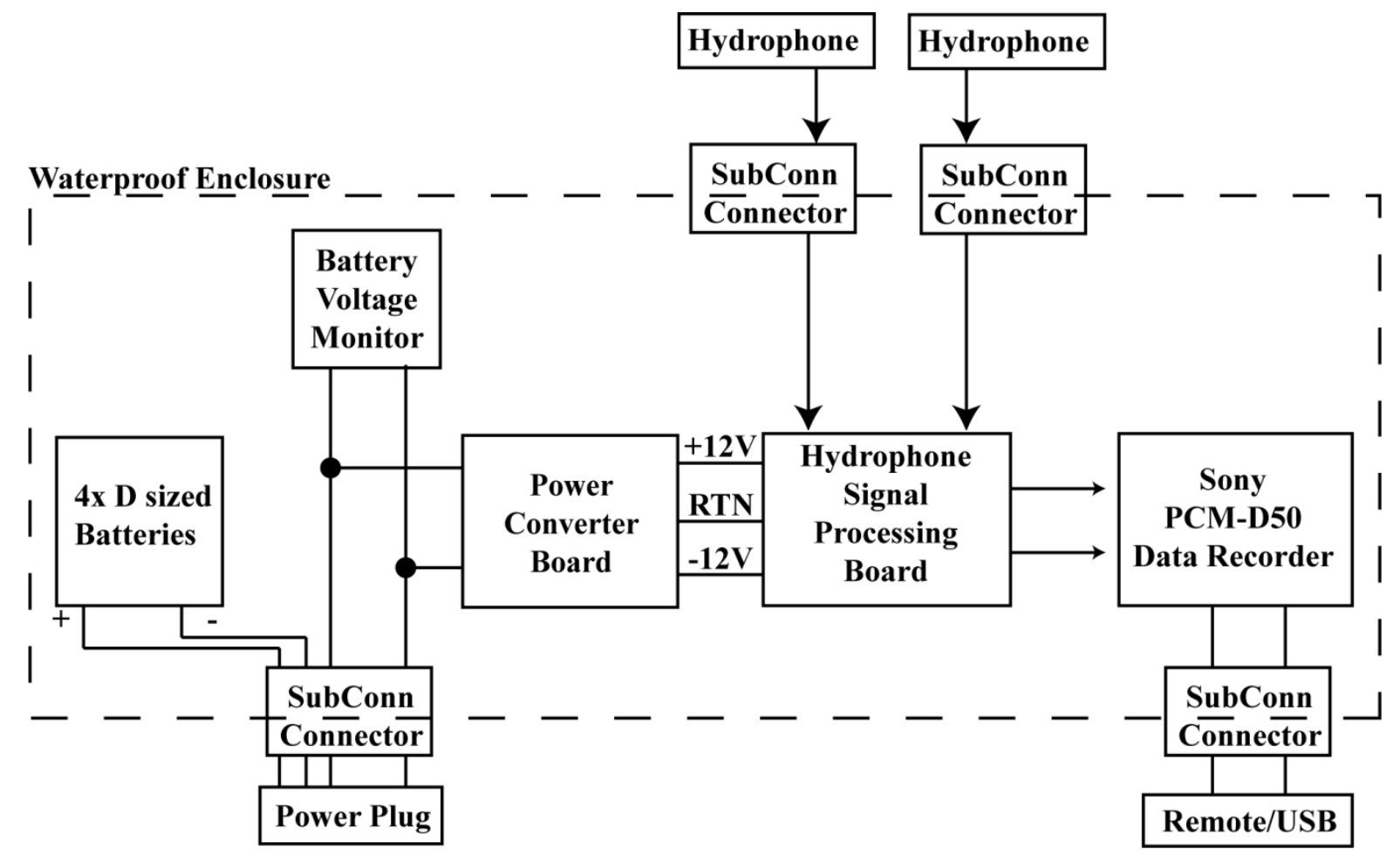

Figure 2.1. Underwater Sound Recorder schematic.

\subsection{Power Converter Board}

The power converter board (Figure 2.2) converts the voltage from the four size D batteries to $\pm 12 \mathrm{~V}$. Voltage conversion is accomplished by two switching regulators (Model LT1533 1A, Linear Technology, Milpitas, California). These regulators were chosen for their fast slew rate. The circuit design achieves a system efficiency of approximately $35 \%$, which results in a battery life of approximately $30 \mathrm{~h}$. The input voltage range of the circuit is 4.4 to $7 \mathrm{~V}$, enabling the use of either alkaline or nickel-metal hydride (NiMH) batteries.

\subsection{Battery Voltage Monitor}

The battery voltage monitor circuit board (Figure 2.3) displays the current battery voltage on a small 3.5-digit liquid crystal display (Model DPM 1AS, Martel Electronics Corporation, Londonderry, New Hampshire). The display enables the user to easily assess battery condition by viewing current battery voltage to determine whether the batteries need to be changed. 


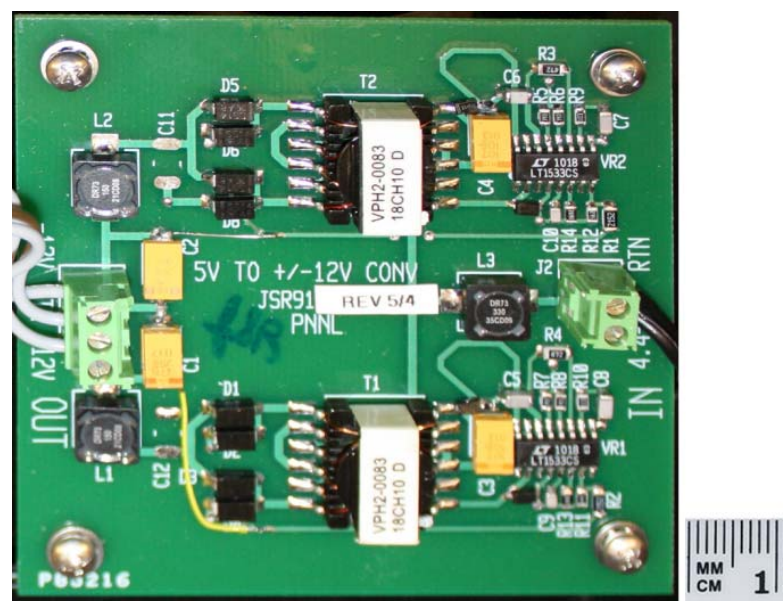

Figure 2.2. Power converter board.

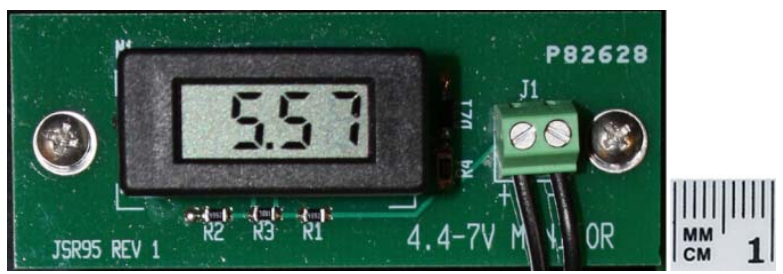

Figure 2.3. Battery voltage monitor.

\subsection{Hydrophone Signal Processing Board}

The hydrophone signal processing board is designed to process the signals from two hydrophones or other sensors in parallel. Each signal begins by going through a 26-dB preamplifier. The signals then pass through a three-pole low-pass Bessel filter (Bianchi and Sorrentino 2007, pp. 31-43) with a cut-off frequency $(-3 \mathrm{~dB})$ of $15 \mathrm{kHz}$. A Bessel filter was chosen for its ability to preserve the shape of the filtered waveform due to its flat group delay. After passing through the filter, the signal goes through a gain stage with user-selectable gain values of $1 \mathrm{x}, 2 \mathrm{x}, 5 \mathrm{x}$, or $10 \mathrm{x}(0 \mathrm{~dB}, 6 \mathrm{~dB}, 14 \mathrm{~dB}$, and $20 \mathrm{~dB})$. The amount of additional gain for each channel is selected by placing a jumper across the appropriate pins (Figure 2.4).

\subsection{Data Recorder}

A data recorder (Model PCM-D50, Sony Corporation, Tokyo, Japan) saves the filtered waveforms (Figure 2.5). The data recorder features a maximum resolution of 24 bits and a maximum sampling rate of $96 \mathrm{kHz}$. The data recorder has 4 gigabytes (GB) of built-in memory, which will allow a total recording time of approximately $1 \mathrm{~h}$ and $55 \mathrm{~min}$ at the maximum resolution and sampling rate. The total amount of memory can be expanded by up to an additional 4 GB by using a Memory Stick Pro-HG Duo memory card (Sony Corporation), although only one type of memory may be used at a time. To start and stop recording with the data recorder from outside the USR enclosure, a wired remote control module (Model 
RM-PCM1, Sony Corporation) is included. The data are saved to the memory as waveform audio files (xxx.wav, also referred to as "wave" files), which can be downloaded from the data recorder through a universal serial bus (USB) connection with a personal computer (PC). To ensure that the gain of the USR is well defined, the knob that controls the recording gain of the data recorder was set to its maximum value and a piece of tape was placed over the knob to prevent the user from unintentionally moving it. At the maximum recording gain, the data recorder provides about $4 \mathrm{~dB}$ of gain.

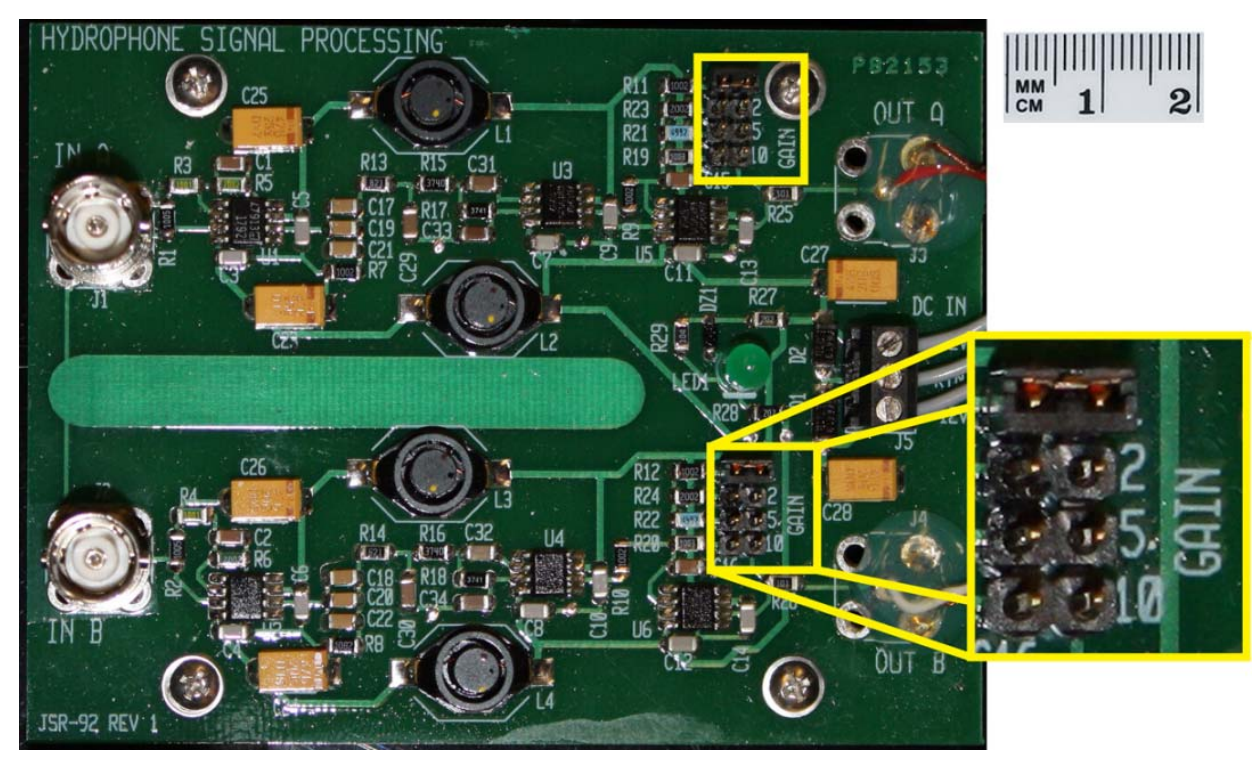

Figure 2.4. Hydrophone signal processing board. The gain selector jumper pins for each channel are highlighted in yellow.

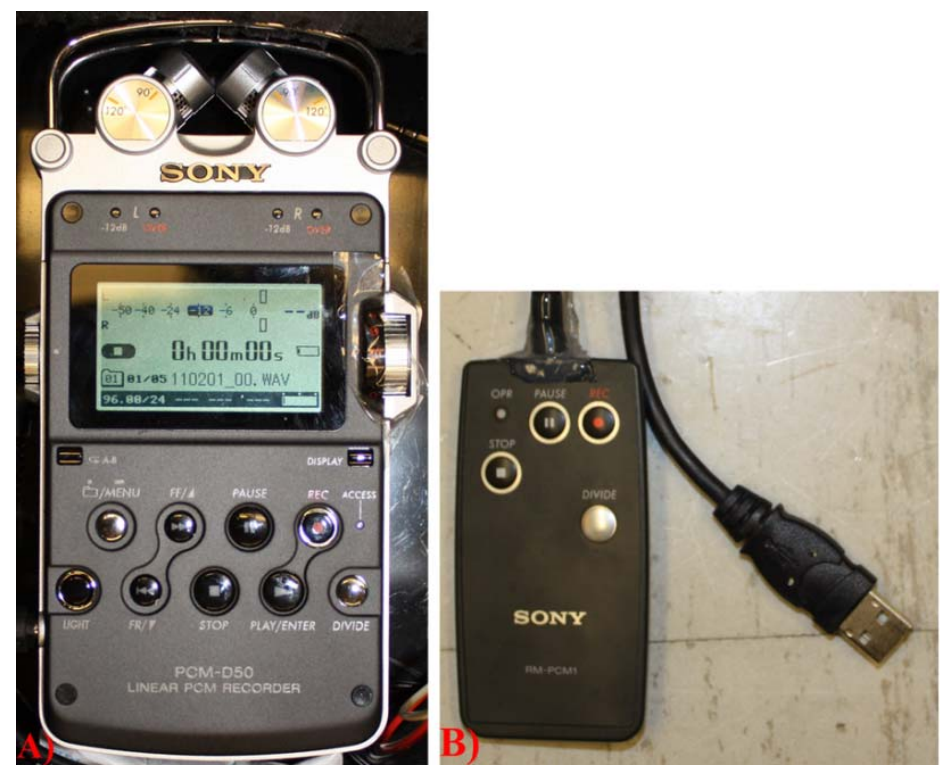

Figure 2.5. PCM-D50 data recorder. A) Data recorder device; B) wired remote control module and terminal connector for a USB cable. 


\subsection{Nonsubmersible Housing}

A Pelican 1400 Case (Pelican Products Inc., Torrance, California) is used for the nonsubmersible version of the USR (Figure 2.6). The outside dimensions of this case are $34.0 \times 29.5 \times 15.2 \mathrm{~cm}$ (excluding connectors). On the side of the case are four underwater mateable connectors (SubConn Inc., Burwell, Nebraska). Two of the connectors are used for connecting each of the hydrophones. If only one hydrophone is to be used, a submersible plug is included to keep the connector terminals dry. Another connector is used for powering up the device by inserting a submersible plug. The fourth connector is for connecting the remote control module, whose cable also includes the USB connector. Similar to the hydrophone connectors, when the remote and USB connection are not needed, a provided submersible plug may be used in its place.

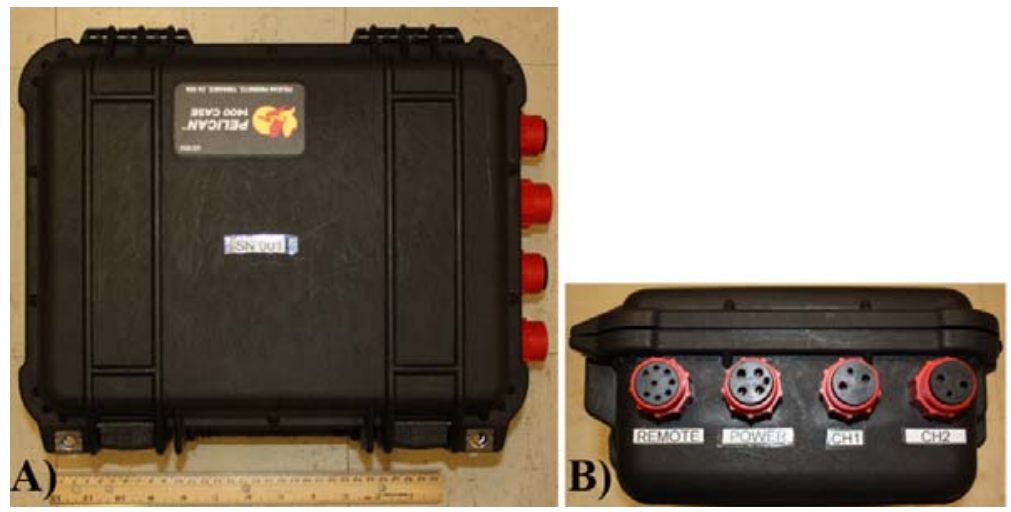

Figure 2.6. Nonsubmersible version of the Underwater Sound Recorder. A) Pelican 1400 case; B) external waterproof connections.

\subsection{Submersible Housing}

For the submersible version of the USR, a submersible housing (Model A8.403SS, PREVCO Subsea LLC, Fountain Hills, Arizona) is used (Figure 2.7). The housing is constructed from aluminum and is rated for a maximum depth of $300 \mathrm{~m}$. The maximum outside diameter is $26.7 \mathrm{~cm}$, and the length (excluding connectors) is $59.0 \mathrm{~cm}$. The mass of the housing in air is $10.9 \mathrm{~kg}$, and $-10.3 \mathrm{~kg}$ in sea water. SubConn underwater mateable connectors, identical to the ones used on the nonsubmersible version of the USR, are used also for connecting the hydrophones, remote control module and USB, and for turning on recorder power.
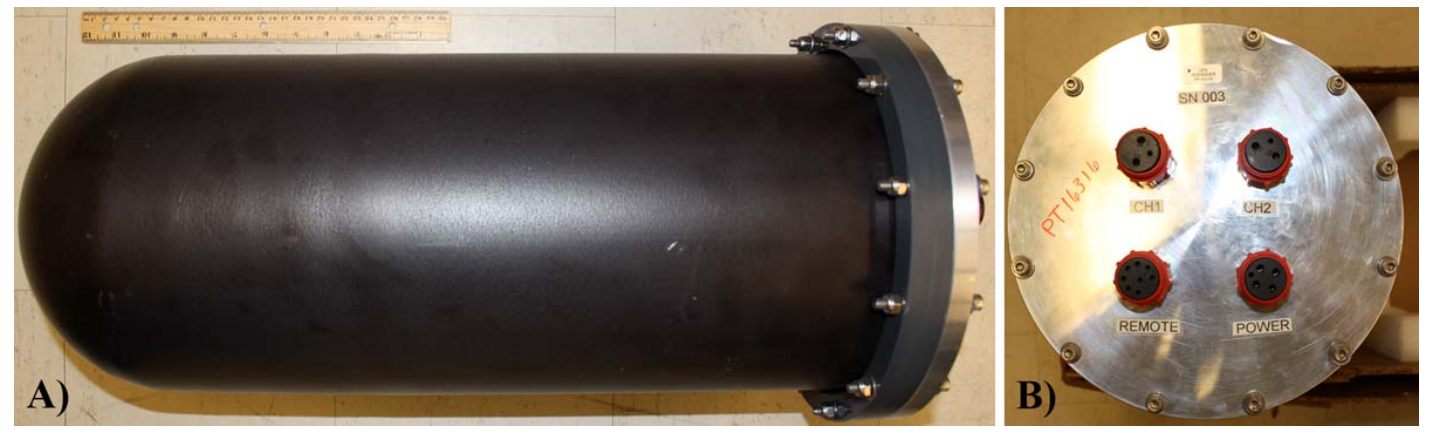

Figure 2.7. Submersible version of the Underwater Sound Recorder. A) PREVCO submersible housing; B) external waterproof connections. 


\subsection{Testing Methods}

To test the hydrophone signal processing board, the PCM-D50 data recorder, and the complete USR system, single-frequency sinusoidal voltages were sent from a data acquisition system, described in subsequent sections, directly to the input of the component being tested. Fifty logarithmically spaced frequencies between $100 \mathrm{~Hz}$ and $50 \mathrm{kHz}$ were sent to the recording system component being tested. Each signal was composed of 1000 cycles per frequency, with 100 sample points per period, except when limited by the maximum sampling rate, which occurred at frequencies higher than $40 \mathrm{kHz}$. After each frequency was sent, the results were analyzed by calculating the root mean square voltages of the signals' input and output from the USR element being tested using Equation (3.1).

$$
V_{R M S}=\sqrt{\frac{\sum_{i=1}^{n} x_{i}^{2}}{n}}
$$

The gain in $\mathrm{dB}$ re $1 \mathrm{~V}$ through the USR element at the test frequency was calculated using Equation (3.2).

$$
\text { Gain }=20 * \log _{10}\left(\frac{V_{R M S_{\text {_out }}}}{V_{R M S_{\_} \text {in }}}\right)
$$

Four different USRs, two of each design, were tested.

\subsection{Hydrophone Signal Processing Board}

The USR hydrophone signal processing boards were tested using a data acquisition card (Model PXIe-6124, National Instruments [NI], Austin, Texas) located in a PXIe-1073 chassis (National Instruments) and connected to a computer running the Microsoft Windows 7 operating system. The NI data acquisition card has a 16-bit analog-to-digital converter (analog input) and a 16-bit digital-to-analog converter (analog output), each with a maximum sampling rate of $4 \mathrm{MHz}$. The data acquisition card was controlled by a MATLAB program (The MathWorks, Inc., Natick, Massachusetts) written specifically for these tests. All data analysis was also conducted using MATLAB programs. One of the PXIe-6124 analog outputs was used to send sinusoidal signals, with a peak-to-peak voltage of $90 \mathrm{mV}$, to one channel of the hydrophone signal processing board. The input of the channel not being tested was terminated with a 50-ohm load. The output of the hydrophone signal processing board was sent to one of the PXIe-6124 analog inputs (Figure 3.1).

The MATLAB program created to test the hydrophone signal processing board enabled completely automated testing of the board. After the script was run, the gain at each frequency was determined; in addition, a graphic displaying the gain as a function of the input frequency was developed. The test was run for each channel with each value of user-selectable gain. To accommodate each of the gain values, the analog input range of the data acquisition card was increased for the increasing amounts of gain. For the $1 \mathrm{x}$ gain selection, $\mathrm{a} \pm 1-\mathrm{V}$ range was used; $2 \mathrm{x}$ was $\pm 2 \mathrm{~V}, 5 \mathrm{x}$ was $\pm 5 \mathrm{~V}$, and $10 \mathrm{x}$ was $\pm 10 \mathrm{~V}$. 


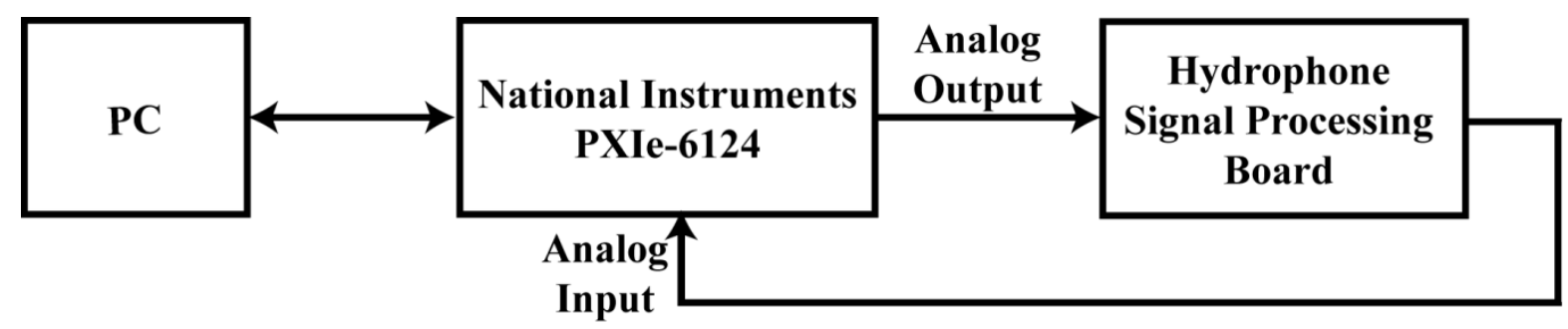

Figure 3.1. Hydrophone signal processing board test schematic.

\subsection{Data Recorder}

The PCM-D50 data recorder was also tested using the NI PXIe-6124 data acquisition card. One of the PXIe-6124 analog outputs was used to send sinusoidal signals, with a peak-to-peak voltage of $1.2 \mathrm{~V}$, to one channel of the PCM-D50 data recorder (Figure 3.2). The other channel of the data recorder was terminated with a 50-ohm load. Each input signal at each test frequency was saved to a separate waveform audio file on the data recorder. This was accomplished by having the MATLAB program prompt the tester when to begin recording and when to stop recording each test frequency on the data recorder. After all of the files were collected, they were transferred for post processing from the data recorder to a computer running MATLAB, through a USB cable that connected the recorder and computer.

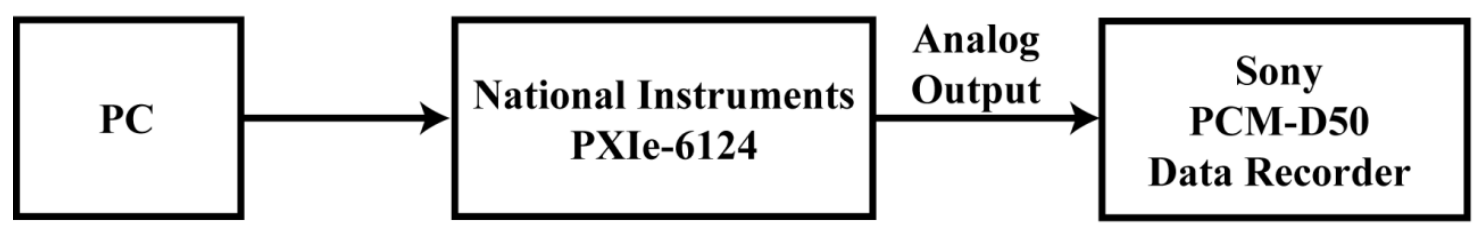

Figure 3.2. PCM-D50 data recorder test schematic.

\subsection{Complete Underwater Sound Recorder System}

The test of the complete USR system followed a process similar to that for the test for the PCM-D50 data recorder alone. The main difference was the voltage of the sinusoidal signals input to the USR. The input voltage at higher USR gain settings had to be kept low to prevent clipping the signals when they were recorded by the PCM-D50. Low voltages with high resolution were generated by attenuating a higher voltage signal from an NI data acquisition card using a Kay Model 837 attenuator (Kay Elemetrics Corp., Lincoln Park, New Jersey). The NI PXIe-6124 was replaced by an NI PCI-6110 data acquisition card for this test to match the impedances of the attenuator and data acquisition card (Figure 3.3). The PCI-6110 has a 12-bit analog-to-digital converter with a maximum sampling rate of $5 \mathrm{MHz}$ and a 16-bit digital-to-analog converter with a maximum sampling rate of $4 \mathrm{MHz}$. The hydrophone signal processing board test described in Section 3.1 was performed on a board using the PCI-6110 data acquisition card and the results compared to those obtained using the NI PXIe-6124 card. Nearly identical results were obtained using both NI cards. This test ensured that the change in NI card would not affect test results. The peak-to-peak voltage of sinusoidal signals output from the PCI-6110 was $50 \mathrm{mV}$. The attenuation set on the Kay 837 attenuator was the same as the gain value set on the hydrophone signal processing board 
for the test being performed $(0 \mathrm{~dB}, 6 \mathrm{~dB}, 14 \mathrm{~dB}$, or $20 \mathrm{~dB})$. The attenuation of the Kay 837 attenuator was measured (Appendix B), and the measured value rather than that assumed from the attenuator setting was used during processing of USR test data.

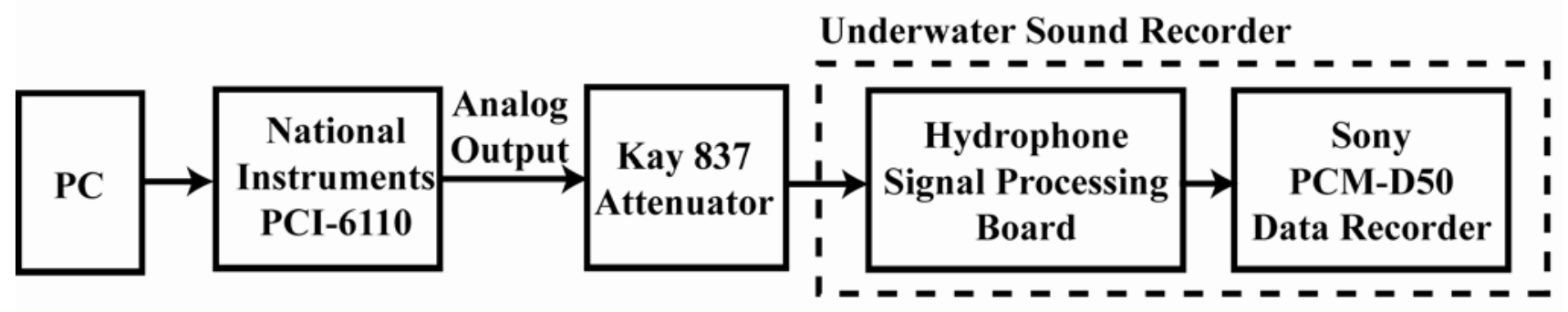

Figure 3.3. Underwater Sound Recorder test schematic.

\subsection{Tank Testing}

Benchtop testing of the USR was followed by in-water tank testing. These tests were conducted to simulate real-world underwater acoustic signals. Two underwater acoustic signals were used (Figure 3.4). The first was an underwater explosion, ${ }^{1}$ and the second was a whale call (STBS 2011).
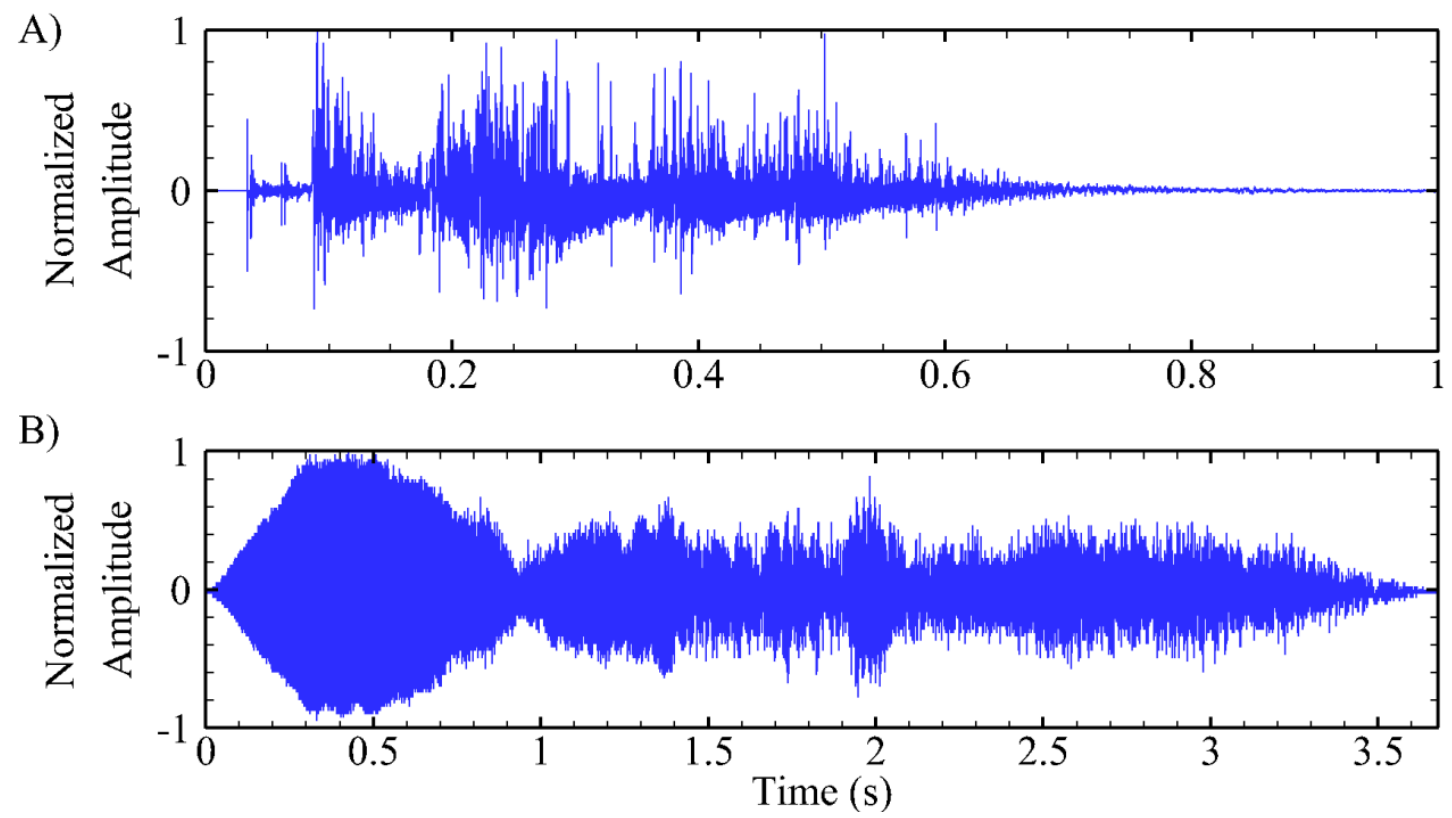

Figure 3.4. Waveforms used for tank testing. A) Underwater explosion; B) whale call.

\footnotetext{
${ }^{1}$ Carlson TJ, CM Woodley, GE Johnson, and JR Skalski. 2011. Compliance Monitoring of Underwater Blasting for Rock Removal at Warrior Point, Columbia River Channel Improvement Project, 2009/2010. Draft report to the U.S. Army Corps of Engineers, Portland District. Pacific Northwest National Laboratory, Richland, Washington.
} 
The testing was performed in a tank measuring $7.32 \mathrm{~m}$ long $\times 3.05 \mathrm{~m}$ wide $\times 1.83 \mathrm{~m}$ deep (Figure 3.5A). The signals were saved as wave files, which were sent from the audio output of a PC to an amplifier (Model IPA 300T, Architectural Acoustics, Corby, Northamptonshire, UK) that was connected to a high-power broadband piezoelectric underwater transducer (Model LL9162T, Lubell Labs Inc., Columbus, Ohio). The underwater transducer was suspended at one-half the water depth along the centerline of the tank about $1.5 \mathrm{~m}$ from one end. A hydrophone (Type 8104, Brüel \& Kjær, Copenhagen, Denmark) was placed in-line with the underwater transducer $1 \mathrm{~m}$ away (Figure 3.5B)
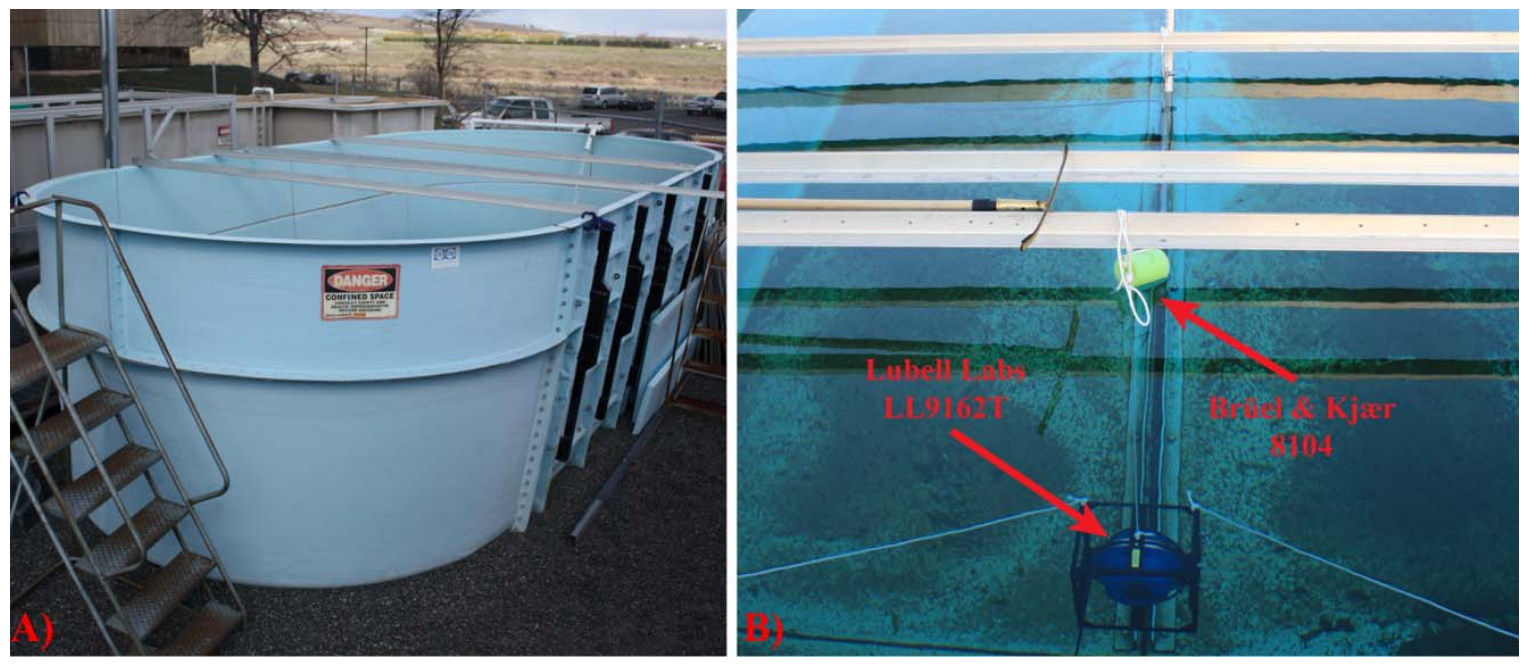

Figure 3.5. Tank testing setup. A) Large elongated oval tank; B) LL9162T underwater transducer and Type 8104 hydrophone.

Each waveform was played and recorded at least five times by the USR (Figure 3.6) for each channel and gain combination for each of the four USRs tested. For each gain value set on the USR, the gain of the IPA 300T was adjusted to avoid any clipping by the PCM-D50 data recorder. Immediately after each of the waveforms was recorded using the USR, the Type 8104 hydrophone was connected to a VP2000 amplifier (Reson Inc., Slangerup, Denmark) that was, in turn, connected to one of the analog inputs on the PXIe-6124 data acquisition card (Figure 3.7). With the same gain set on the IPA 300T amplifier, each waveform was recorded to the computer at least five times using the PXIe-6124 data acquisition card. To prevent any clipping of the waveform, the gain of the VP2000 and the input range on the PXIe-6124 were adjusted for each signal recorded. The gain of the VP2000 was verified (Appendix B) and used during processing of recorded signals.

After the signals were recorded using both the USRs and the PXIe-6124 data acquisition card for each USR channel and gain combination, the recorded waveforms were scaled using the corresponding gain of the USR, as measured in Section 3.3, and the gain of the VP2000. The sensitivity of the hydrophone was then used to convert the units from voltage to pressure. With the waveforms scaled and converted to pressure units, a fast Fourier transform was performed on each waveform (Cooley and Tukey 1965) to determine the frequency content of the recorded signals, the resulting spectra were normalized by the waveform length to determine the frequency content in physical units of pressure, and the results were averaged for each set of measurements. Finally, the maximum pressure from the spectrum for the results obtained from the USR was compared with the results from the PXIe-6124 data acquisition card. 


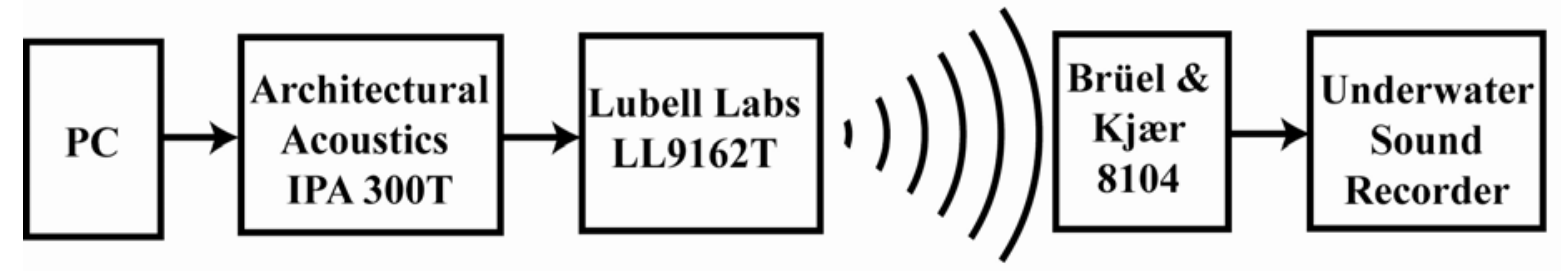

Figure 3.6. Tank testing schematic for Underwater Sound Recorder.

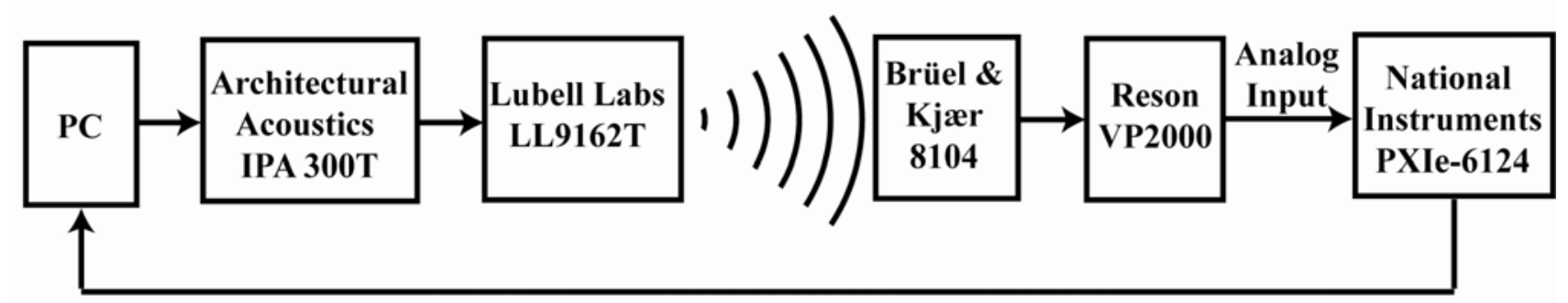

Figure 3.7. Schematic for testing the acquisition performance of the National Instruments PXIe-6124 data acquisition card. 



\subsection{Testing Results and Discussion}

\subsection{Hydrophone Signal Processing Board}

The results of the test on the hydrophone signal processing boards (Figure 4.1 and Table 4.1) show that the observed gain was on average about $0.35 \mathrm{~dB}$ higher than the designed values. Between the four different hydrophone signal processing boards tested, the gain values measured were very similar, with an average standard deviation of only $0.02 \mathrm{~dB}$. The cutoff frequency for the low-pass filter, defined as the point at which the gain has dropped by $3 \mathrm{~dB}$, had an average value of $15.1 \mathrm{kHz}$. The cutoff frequency was highest for the 1x gain setting, with a value of $15.5 \mathrm{kHz}$, and decreased with increasing gain to a value of $14.2 \mathrm{kHz}$ at a gain setting of $10 \mathrm{x}$.

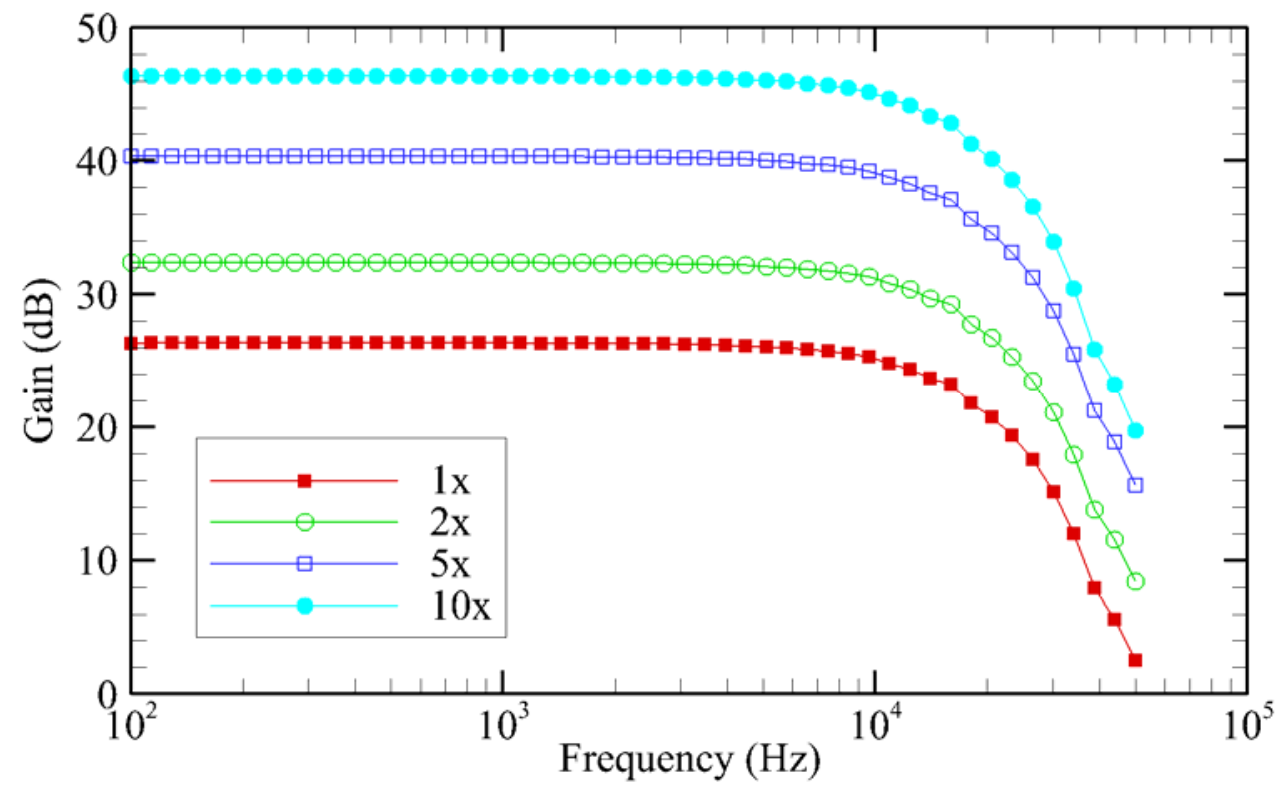

Figure 4.1. Average hydrophone signal processing board frequency response for each gain setting.

Table 4.1. Hydrophone signal processing board average and standard deviation of the gain at $100 \mathrm{~Hz}$ for each gain setting.

\begin{tabular}{cccc}
\hline $\begin{array}{c}\text { Gain } \\
\text { Setting }\end{array}$ & $\begin{array}{c}\text { Average Gain at } 100 \mathrm{~Hz} \\
(\mathrm{~dB} \text { re } 1 \mathrm{~V})\end{array}$ & $\begin{array}{c}\text { Standard Deviation } \\
(\mathrm{dB} \text { re 1V) }\end{array}$ & $\begin{array}{c}-3 \text { dB Cutoff } \\
\text { Frequency }(\mathrm{kHz})\end{array}$ \\
\hline $1 \mathrm{x}$ & 26.35 & 0.02 & 15.5 \\
$2 \mathrm{x}$ & 32.36 & 0.02 & 15.4 \\
$5 \mathrm{x}$ & 40.32 & 0.03 & 15.1 \\
$10 \mathrm{x}$ & 46.35 & 0.02 & 14.2 \\
\hline
\end{tabular}




\subsection{Data Recorder}

The results of the test on the different PCM-D50 data recorders (Figure 4.2 and Table 4.2) indicate that the gain is slightly more variable than that of the hydrophone signal processing boards. The average gain was $4.15 \mathrm{~dB}$, with a standard deviation of $0.25 \mathrm{~dB}$. The cutoff frequency for the data recorders was very consistent, with a value of $44.3 \mathrm{kHz}$ and a standard deviation of only $6 \mathrm{~Hz}$. This cutoff frequency is very close to the Nyquist frequency of $48 \mathrm{kHz}$, which is the largest possible frequency that can be measured with a $96-\mathrm{kHz}$ sampling rate.

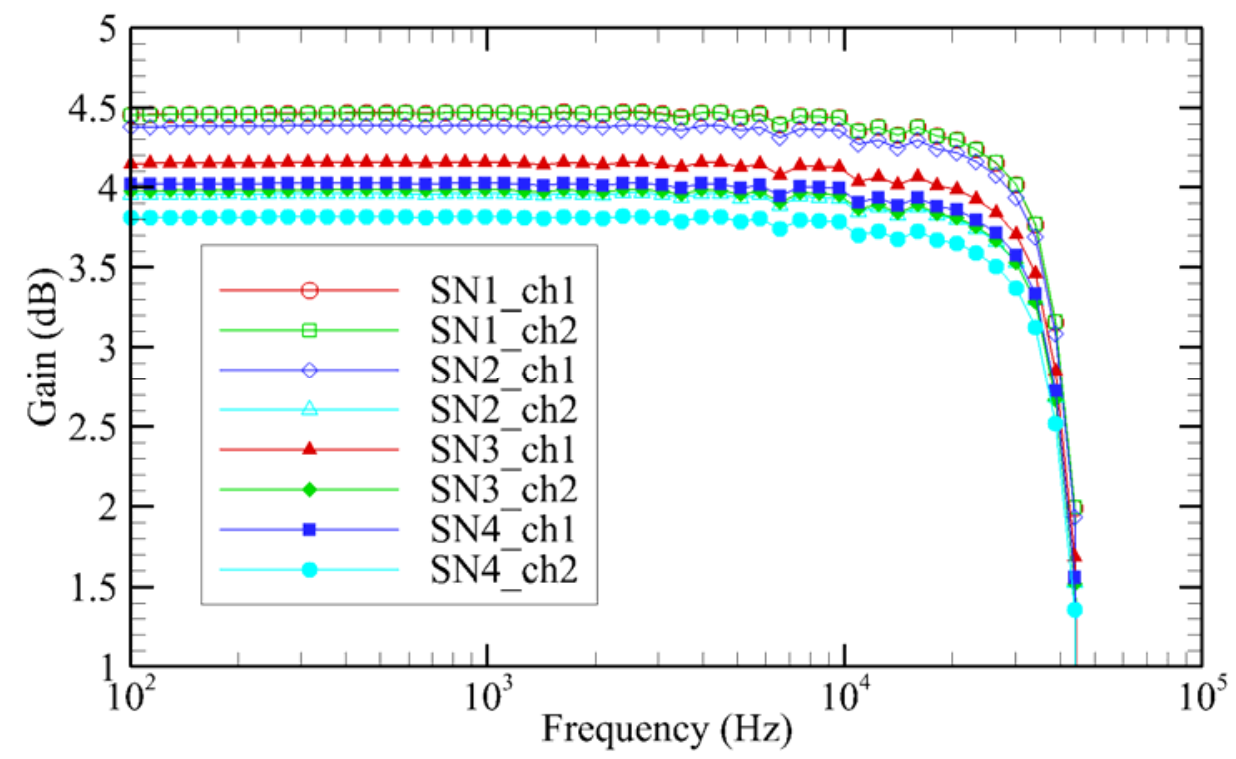

Figure 4.2. PCM-D50 data recorder frequency response for each channel of each unit tested.

Table 4.2. PCM-D50 data recorder gain at $100 \mathrm{~Hz}$ for each channel of each unit tested.

\begin{tabular}{cccc}
\hline $\begin{array}{c}\text { USR Serial } \\
\text { Number }\end{array}$ & $\begin{array}{c}\text { Channel } \\
\text { Number }\end{array}$ & $\begin{array}{c}\text { Gain at 100 Hz } \\
(\mathrm{dB} \text { re 1V) }\end{array}$ & $\begin{array}{c}-3 \mathrm{~dB} \text { Cutoff } \\
\text { Frequency }(\mathrm{kHz})\end{array}$ \\
\hline 1 & 1 & 4.45 & 44.3 \\
1 & 2 & 4.45 & 44.3 \\
2 & 1 & 4.38 & 44.3 \\
2 & 2 & 3.95 & 44.3 \\
3 & 1 & 4.15 & 44.3 \\
3 & 2 & 3.98 & 44.3 \\
4 & 1 & 4.02 & 44.3 \\
4 & 2 & 3.81 & 44.3 \\
\hline \multicolumn{4}{c}{} \\
& Average & 4.15 & \\
\hline
\end{tabular}




\subsection{Complete Underwater Sound Recorder System}

As expected, the gain of the complete USR system (Figure 4.3 and Table 4.3) was very similar to the gain calculated from the sum of the gain values for the hydrophone signal processing board and the PCMD50 data recorder (Table 4.4). The average difference between the actual system gain and the calculated gain was only $0.02 \%$. Such a small difference helps to strengthen the validity of the tests. The cutoff frequencies of the complete USR systems were on average about $0.5 \mathrm{kHz}$ less than the hydrophone signal processing boards alone, with an average value of $14.6 \mathrm{kHz}$.

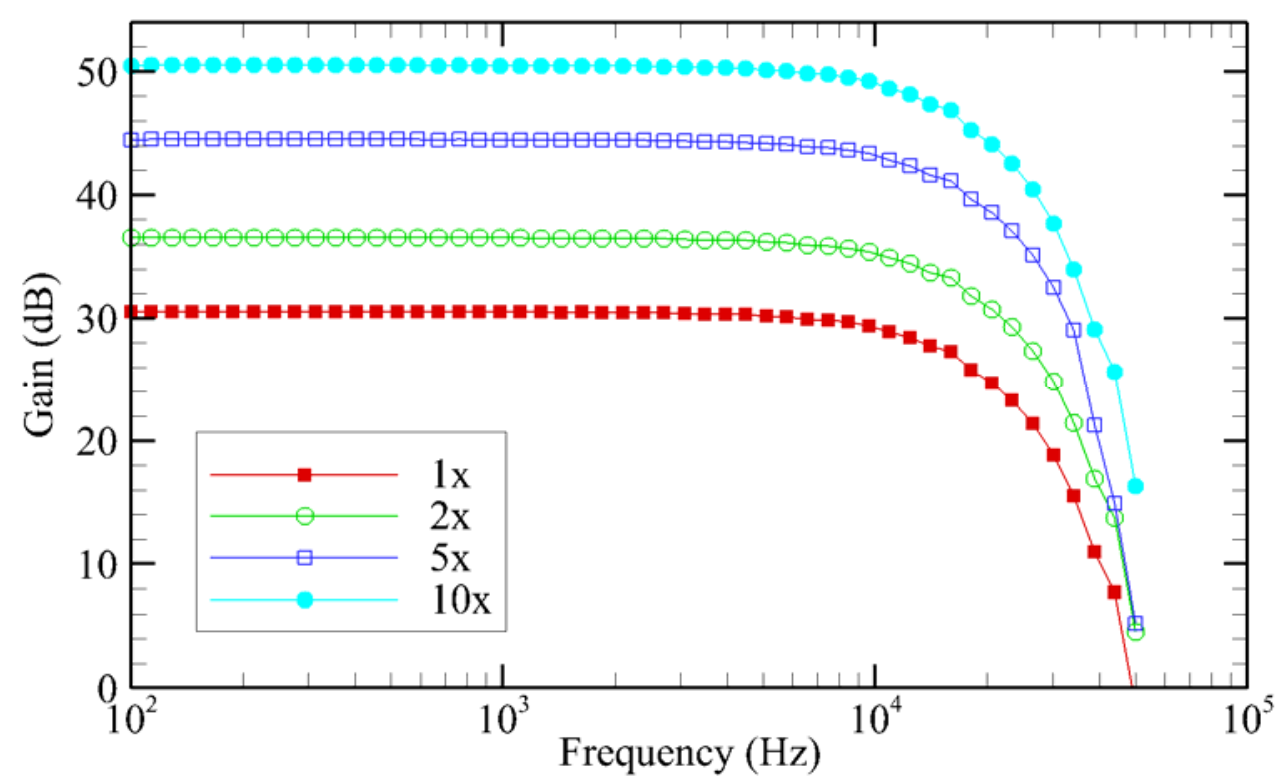

Figure 4.3. Underwater Sound Recorder system average frequency response for each gain setting.

Table 4.3. Underwater Sound Recorder system average and standard deviation of the gain at $100 \mathrm{~Hz}$ for each gain setting.

\begin{tabular}{cccc}
\hline $\begin{array}{c}\text { Gain } \\
\text { Setting }\end{array}$ & $\begin{array}{c}\text { Average Gain at 100 Hz } \\
(\text { dB re 1V) }\end{array}$ & $\begin{array}{c}\text { Standard Deviation } \\
(\mathrm{dB} \text { re 1V) }\end{array}$ & $\begin{array}{c}-3 \text { dB Cutoff } \\
\text { Frequency (kHz) }\end{array}$ \\
\hline $1 \mathrm{x}$ & 30.51 & 0.28 & 14.9 \\
$2 \mathrm{x}$ & 36.52 & 0.28 & 14.9 \\
$5 \mathrm{x}$ & 44.48 & 0.26 & 14.6 \\
$10 \mathrm{x}$ & 50.50 & 0.27 & 13.8 \\
\hline
\end{tabular}


Table 4.4. Comparison between gain from complete Underwater Sound Recorder system test and the sum of the results from the hydrophone signal processing board and the PCM-D50 data recorder tests.

\begin{tabular}{|c|c|c|c|}
\hline & $\begin{array}{l}\text { USR } \\
\text { System }\end{array}$ & Sum of Components & \\
\hline Gain Setting & $\begin{array}{l}\text { Average Gain at } \\
100 \mathrm{~Hz}(\mathrm{~dB} \text { re } 1 \mathrm{~V})\end{array}$ & $\begin{array}{l}\text { Average Gain at } \\
100 \mathrm{~Hz}(\mathrm{~dB} \text { re } 1 \mathrm{~V})\end{array}$ & $\begin{array}{l}\text { Difference } \\
\quad(\%)\end{array}$ \\
\hline $1 \mathrm{x}$ & 30.51 & 30.50 & 0.04 \\
\hline $2 \mathrm{x}$ & 36.52 & 36.51 & 0.03 \\
\hline $5 \mathrm{x}$ & 44.48 & 44.47 & 0.02 \\
\hline $10 \mathrm{x}$ & 50.50 & 50.50 & 0.00 \\
\hline
\end{tabular}

\subsection{Tank Testing}

Overall, the measurements of the two waveforms using the USR systems and the PXIe-6124 data acquisition card compared very well. The measurements of the whale call (Table 4.5) agreed more closely than the measurements of the underwater explosion (Table 4.6). This could be a result of the fact that the bandwidth of the whale call is much lower than that of the underwater explosion (Figure 4.4). The overall average percentage difference of the whale call measurements was $1.4 \%$; the $2 \mathrm{x}$ gain setting had the largest average difference of $4.7 \%$. For the underwater explosion measurements, the overall average percentage difference was $3.0 \%$, with the $2 \mathrm{x}$ gain setting having the largest average difference of $6.1 \%$.

Table 4.5. Percentage difference between the results from the PXIe-6124 measurements and the Underwater Sound Recorder measurements for the whale call waveform.

\begin{tabular}{lcccc}
\hline & $1 \times$ Gain & 2x Gain & $5 x$ Gain & 10x Gain \\
\hline Average & $0.3 \%$ & $4.7 \%$ & $0.3 \%$ & $0.3 \%$ \\
Std. Dev. & $0.5 \%$ & $0.6 \%$ & $0.3 \%$ & $0.5 \%$ \\
\hline
\end{tabular}

Table 4.6. Percentage difference between the results from the PXIe- 6124 measurements and the Underwater Sound Recorder measurements for the underwater explosion waveform.

\begin{tabular}{lcccc}
\hline & $1 \times$ Gain & 2x Gain & 5x Gain & 10x Gain \\
\hline Average & $2.5 \%$ & $6.1 \%$ & $1.9 \%$ & $1.5 \%$ \\
Std. Dev. & $1.7 \%$ & $1.2 \%$ & $0.8 \%$ & $1.0 \%$ \\
\hline
\end{tabular}



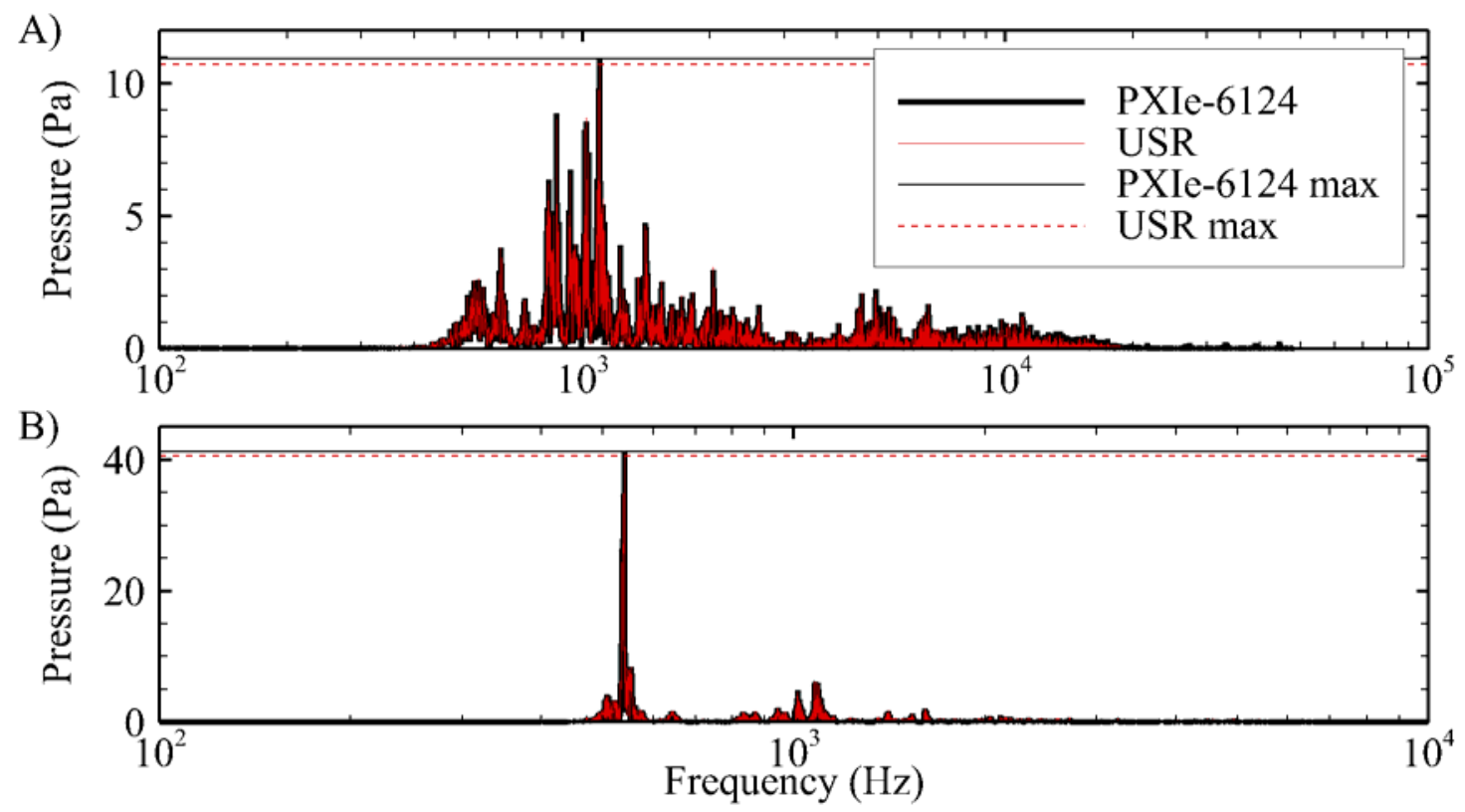

Figure 4.4. Sample spectrum comparisons from the tank testing. A) Underwater explosion; B) whale call. 



\subsection{Conclusions}

The primary objective of this project was to design, build, and test a portable, watertight, and easy-touse device to record underwater acoustic signals for the U.S. Department of Energy Wind \& Water Power Program. Researchers and engineers at the Pacific Northwest National Laboratory have accomplished this by designing a device called the Underwater Sound Recorder (USR). The device allows up to $1 \mathrm{~h}$ and $55 \mathrm{~min}$ of data to be collected from two sensors simultaneously. The USR filters out frequency components above $15 \mathrm{kHz}$ and lets the total system gain be adjusted to $30 \mathrm{~dB}, 36 \mathrm{~dB}, 44 \mathrm{~dB}$, or $50 \mathrm{~dB}$ independently for each sensor. Tests performed in the laboratory using a data acquisition system to send single-frequency sinusoidal voltages directly to the each component have verified that the device operates as designed.

The compact USR enables the collection of underwater acoustic field measurements. To increase system versatility, two versions of the USR were designed and built. Both versions feature identical components housed in a watertight enclosure. The primary difference is that one version is designed to be completely submersed in water, and the other is intended for surface-side operation.

The submersible version allows the device to be connected to two hydrophones and deployed to a maximum depth of $300 \mathrm{~m}$. This makes the submersible version appropriate for applications where it is desirable to collect long-duration measurements at depths that would require very long hydrophone cables or extension cables, which can introduce additional noise to the measurements. Examples of uses for the submersible version include recording sounds generated by vessels or the vocalizations of some marine mammals, where the start and end times of the acoustic signals are not known and the deployment area of a study site may be more isolated.

The nonsubmersible version is better suited for applications in which the underwater event to be monitored has a relatively short duration and a known start and end time; with the nonsubmersible version, researchers can use the remote control module and USB connector to easily start recording, stop recording, and extract the data. Because the nonsubmersible version is still watertight, it can be safely operated in a boat or from the shore in nearly all weather conditions. Typical activities for which the nonsubmersible version is appropriate include monitoring underwater processes such as underwater explosions or pile driving. In these processes, several events occur at known times, making it highly desirable to record multiple files containing only the desired events. Recording data spanning only the signals of interest can significantly reduce the time to post-process the collected data. 



\subsection{References}

Bianchi G and R Sorrentino. 2007. Electronic Filter Simulation and Design. McGraw-Hill Professional, New York.

Cooley J and J Tukey. 1965. An algorithm for the machine computation of the complex Fourier series. Mathematics of Computation 19:297-301.

Govoni JJ, LR Settle, and MA West. 2003. Trauma to juvenile pinfish and spot inflicted by submarine detonations. Journal of Aquatic Animal Health 15:111-119.

Govoni JJ, MA West, LR Settle, RT Lynch, and MD Greene. 2008. Effects of underwater explosions on larval fish: Implications for a coastal engineering project. Journal of Coastal Research 24(sp 2):228233.

Popper AN, J Fewtrell, ME Smith, and RD McCauley. 2004. Anthropogenic sound: Effects on the behavior and physiology of fishes. Marine Technological Science Journal 37:35-40.

Popper AN, TJ Carlson, AD Hawkins, BL Southall, and RL Gentry. 2006. Interim Criteria for Injury of Fish Exposed to Pile Driving Operations: A White Paper. Available at http://www.wsdot.wa.gov/ NR/rdonlyres/84A6313A-9297-42C9-BFA6-750A691E1DB3/0/BA_PileDrivingInterimCriteria.pdf (May 2011).

STBS. 2011. Whale.wav. Simply the Best Sounds. Available at http://simplythebest.net/sounds/ WAV/sound_effects_WAV/animals_wavs_4.html (March 2011).

Teleki GC and AJ Chamberlain. 1978. Acute effects of underwater construction blasting on fishes in Long Point Bay, Lake Erie. Fisheries Research Board of Canada 35:1191-1198.

Wiley ML, JB Gaspin, and JF Goertner. 1981. Effects of underwater explosions on fish with a dynamical model to predict fishkill. Ocean Science and Engineering 6(2):223-284. 

Appendix A

Schematics 



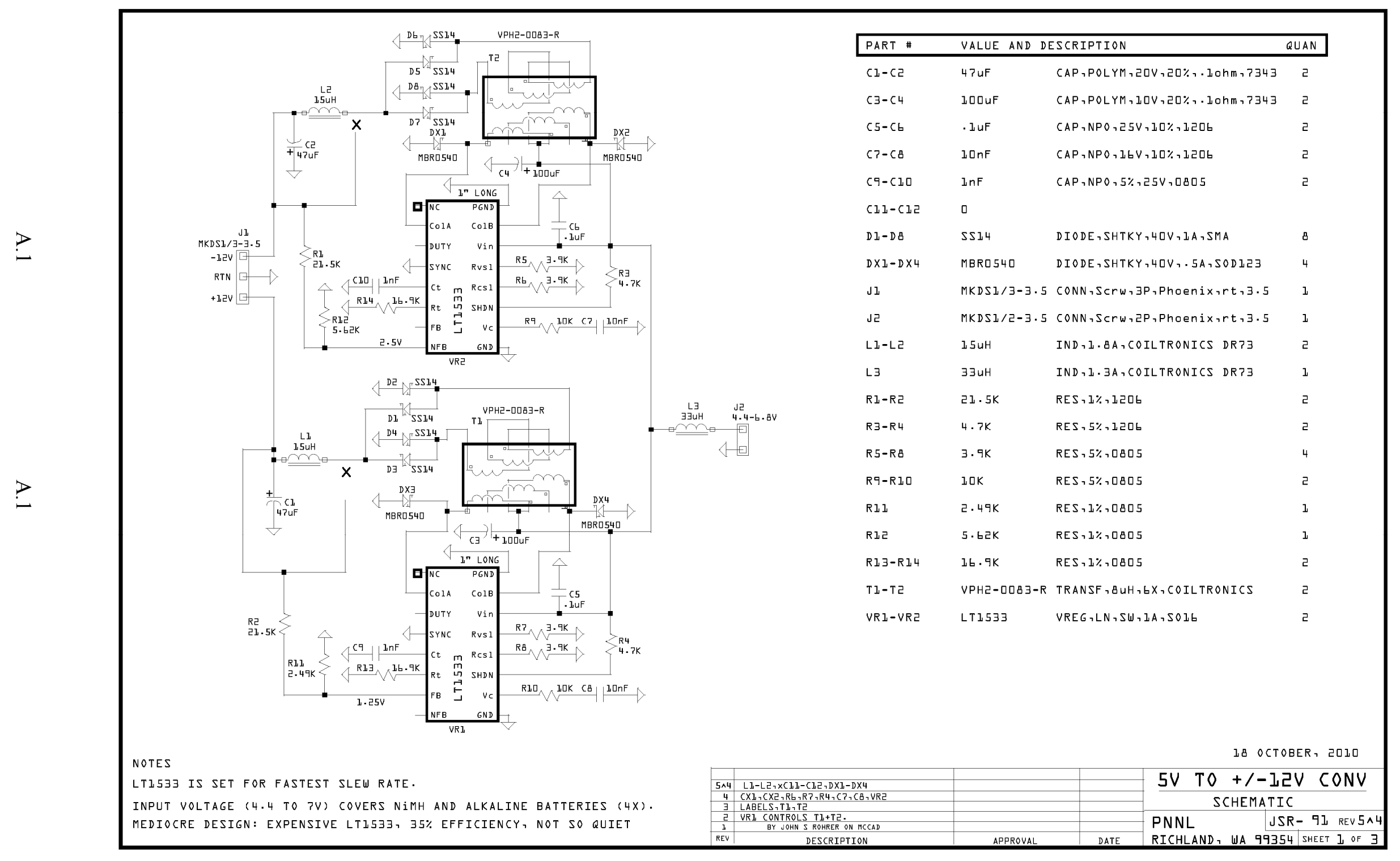




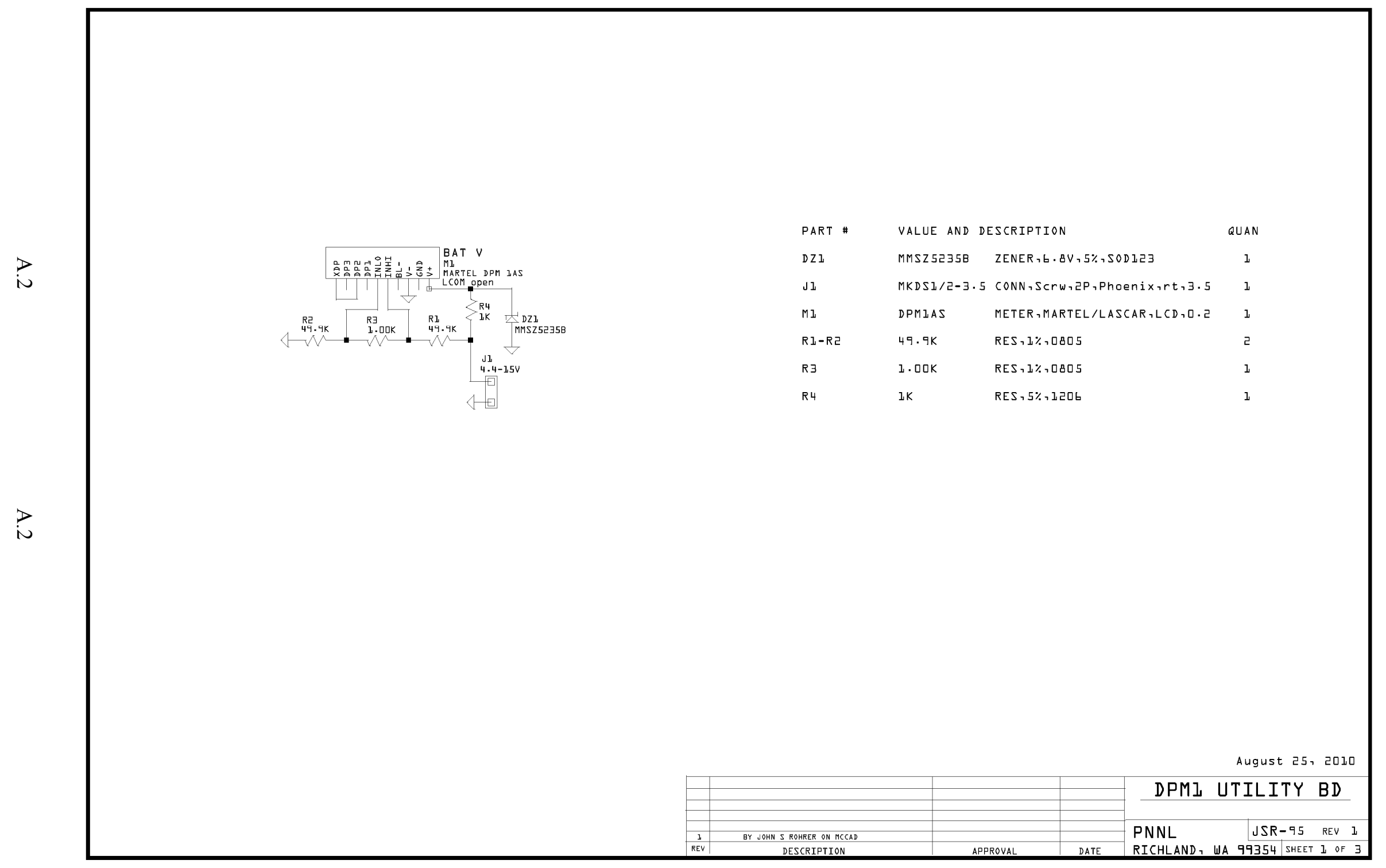




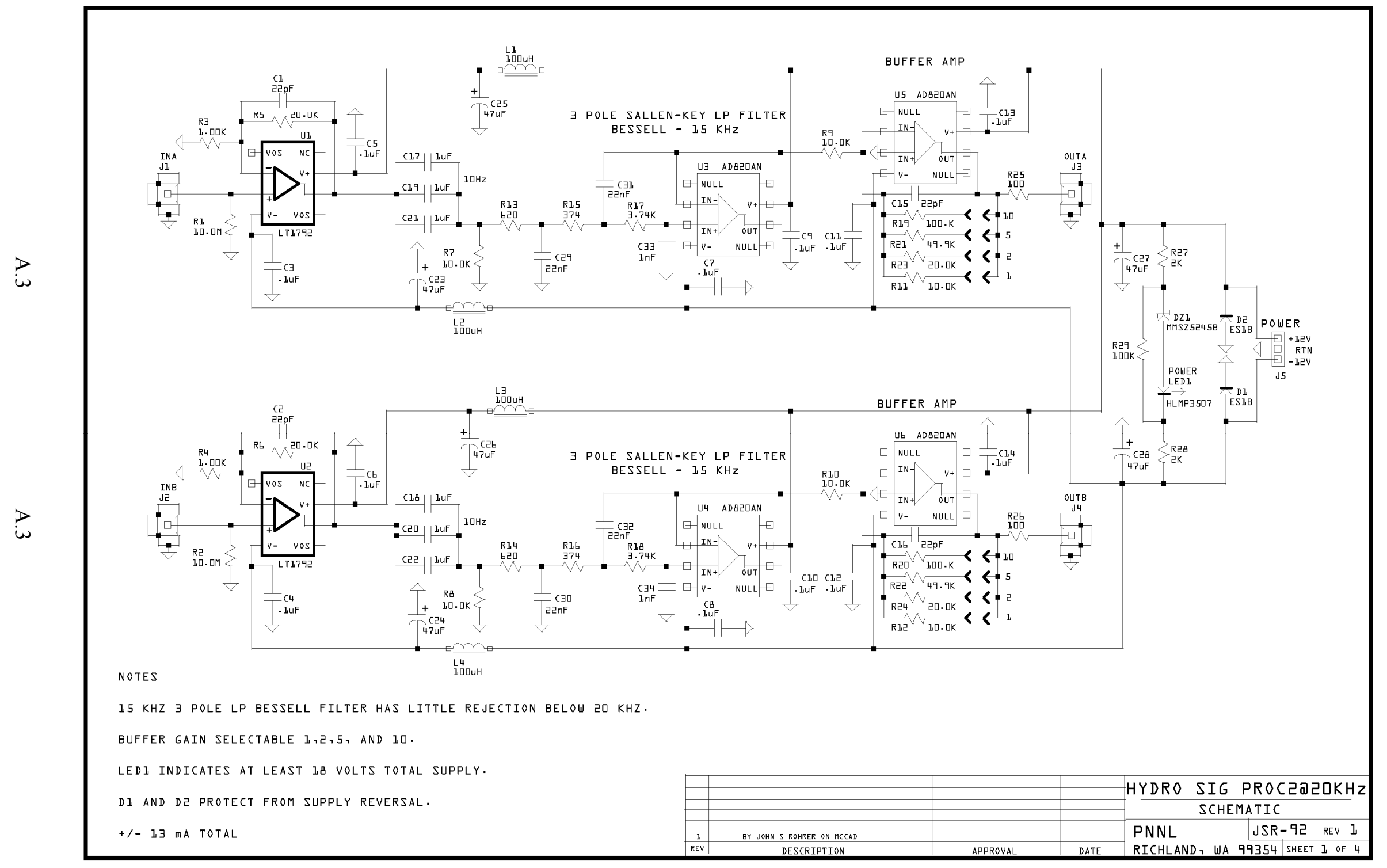




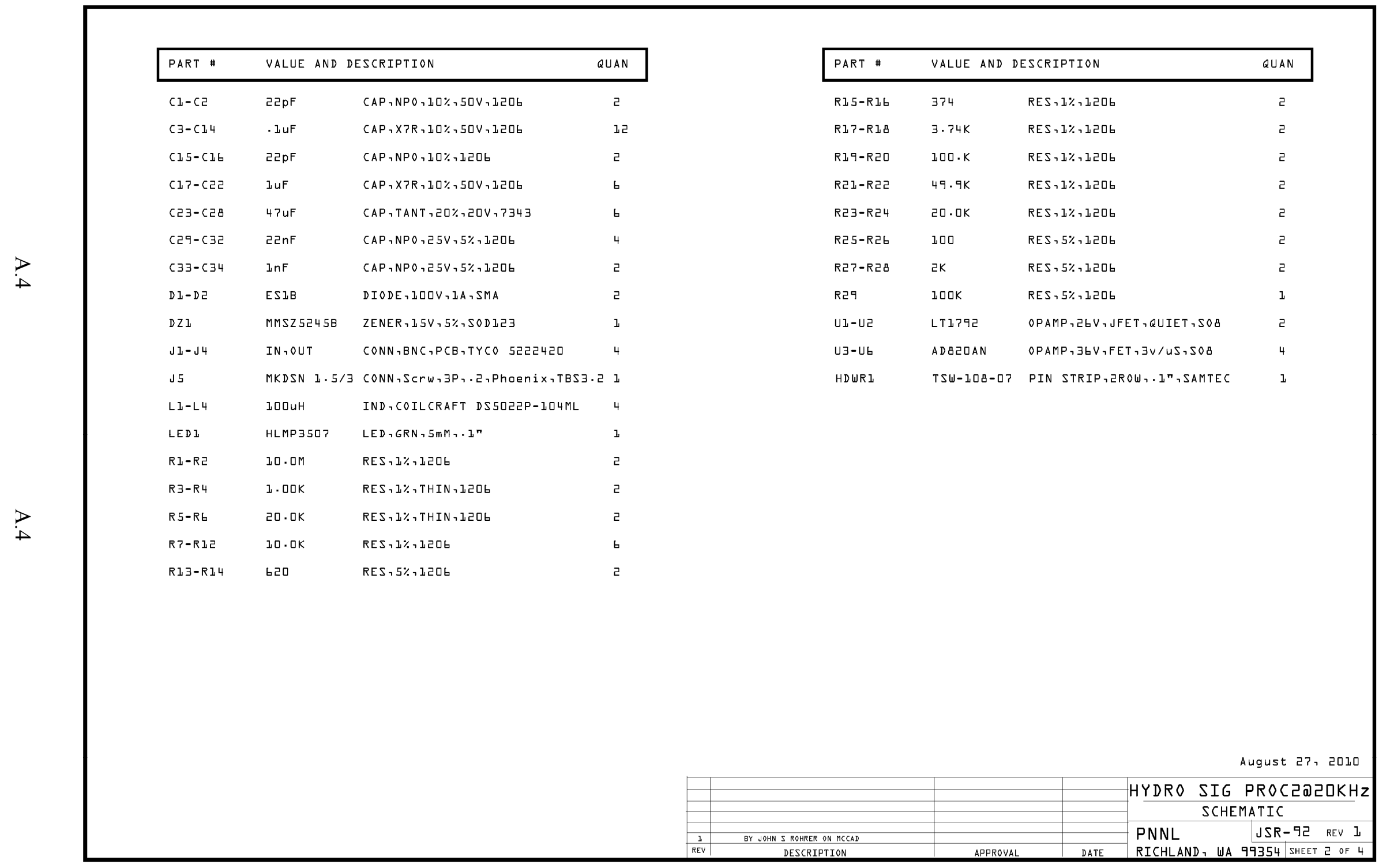




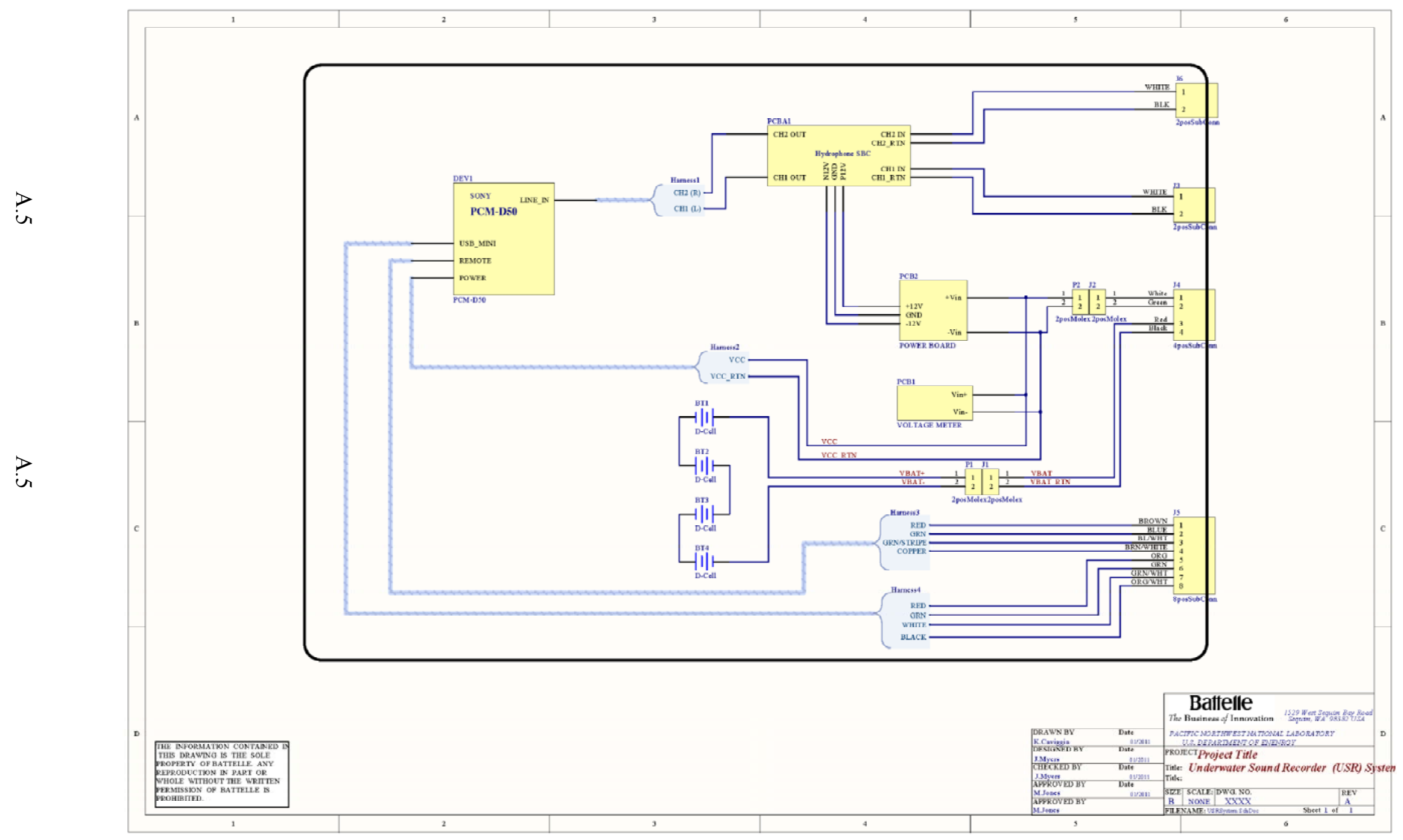



Appendix B

\section{Test Component Frequency Response}





\section{Appendix B}

\section{Test Component Frequency Response}
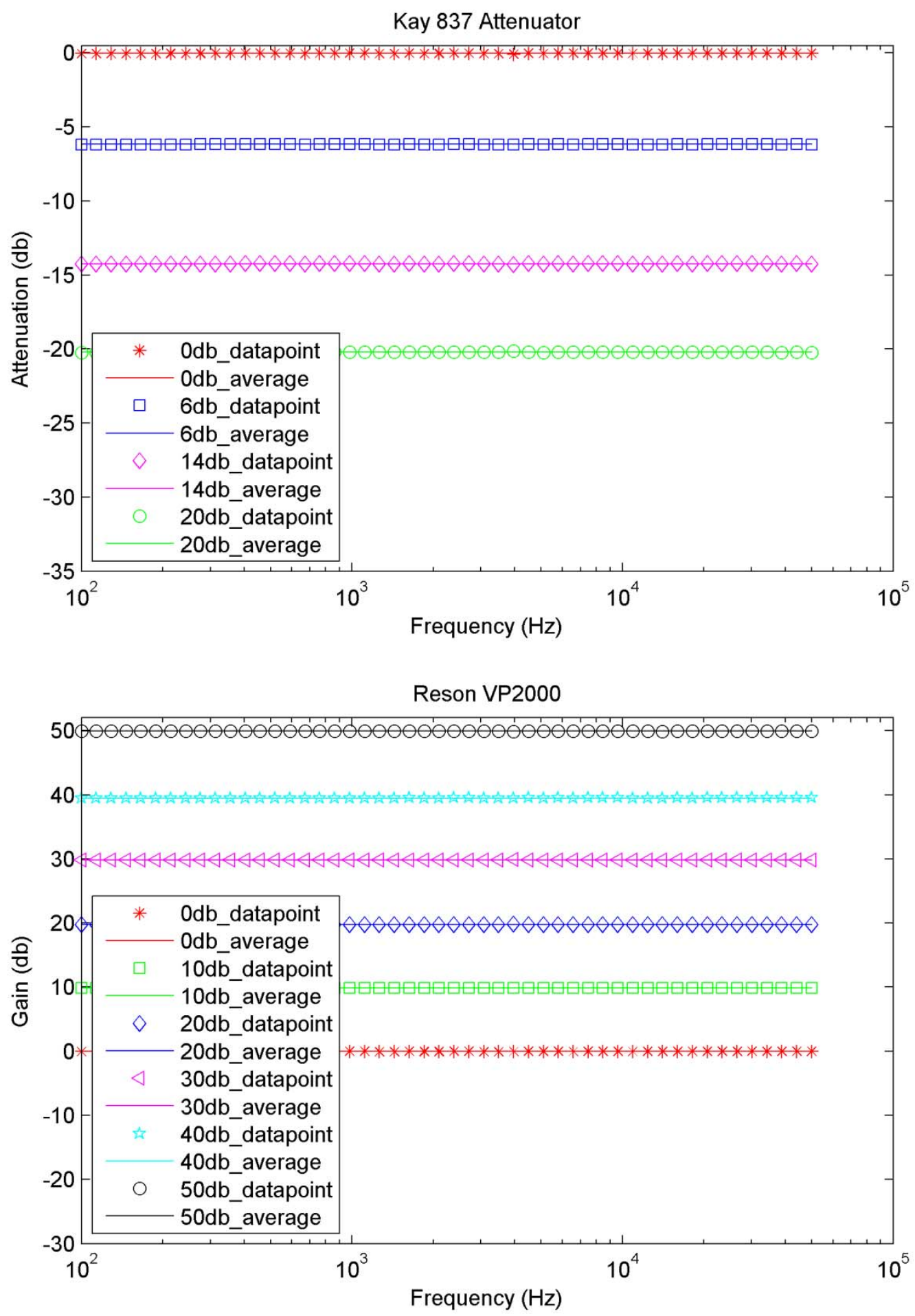

B.1

For Review Only - Do Not Cite 



\section{Appendix C}

\section{Underwater Sound Recorder Users Guide}





\section{Appendix C}

\section{Underwater Sound Recorder User's Guide}

\section{C.1 Type I: Nonsubmersible Enclosure}

The nonsubmersible version of the USR is intended for surface-side operation. The unit was designed for field configuration and portability. The case provides user access during operation, for tasks such as monitoring battery voltage and replacing batteries.

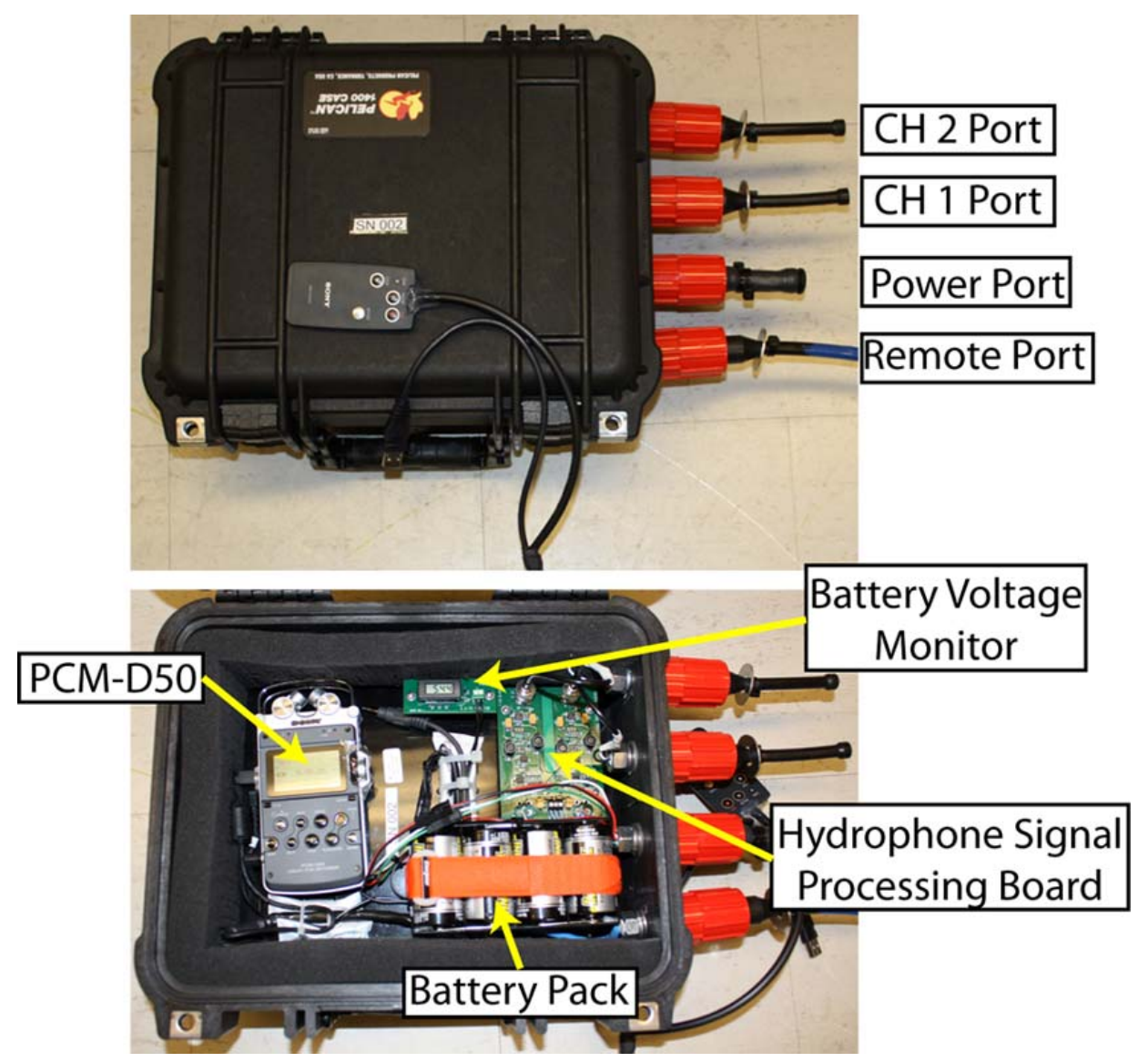

\section{C.2 Type II: Submersible Enclosure}

The submersible version of the USR contains the same components as the nonsubmersible version described in Section C.1. The end cap to the unit is secured with 12 bolts and contains two O-rings. When disassembling, remove the end cap approximately $0.5 \mathrm{in}$. from the housing and remove all connections, including two Bayonet Neill-Concelman (BNC) connectors, two battery power connectors, USB connector, and the remote connections. During reassembly, make sure to use O-ring lubricant (high- 
vacuum grease) and verify that all connections are made. Be sure to tighten the bolts in a "star" configuration. Do not completely tighten bolts until all bolts have been started.
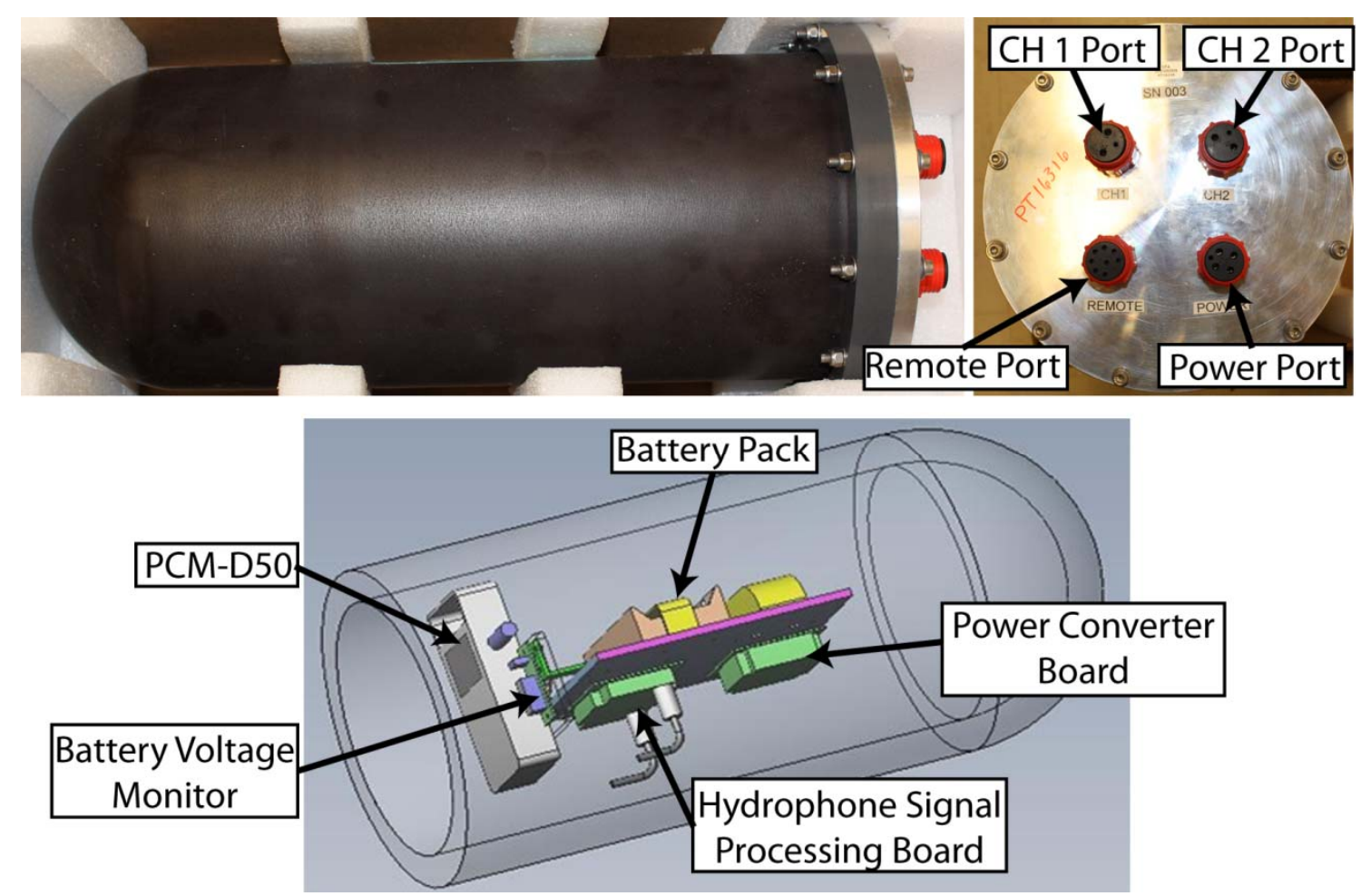

\section{C.3 Connections}

\section{Power Port}

The power port provides a connection from the battery pack to the system.

\section{Remote Port}

The remote port enables control capabilities on the PCM-D50 data recorder, including accessing data through a standard USB connection.

\section{Channel 1 Port}

This port provides a hydrophone input signal to the BNC connector labeled IN B on the hydrophone signal processing board (CH $1 \rightarrow$ IN B). Audio data is captured on the left channel of the Sony PCMD50 data recorder. 


\section{Channel 2 Port}

This port provides a hydrophone input signal to the BNC connector labeled IN A on the hydrophone signal processing board ( $\mathrm{CH} 2 \rightarrow$ IN A). Audio data is captured on the right channel of the Sony PCMD50 data recorder.

\section{Data Recorder}

If the data recorder is left unpowered, the firmware settings on the unit will remain in memory for approximately 2 weeks. The default switched (external) settings are Line Input, Gain switched to 0, Volume set to 10 , power set to $\mathrm{ON}$ for the unit. The firmware default settings are $96.0-\mathrm{kHz}$ sample rate and 24 bits per sample; default storage is the memory stick.

\section{Battery Voltage Monitor}

The meter provides a read-out of battery voltage. Operational voltages lower than $5 \mathrm{~V}$ will require a battery change.

\section{Hydrophone Signal Processing Board}

The gain for each channel can be adjusted to $1 \mathrm{x}, 2 \mathrm{x}, 5 \mathrm{x}$, or $10 \mathrm{x}$ by simply changing a single jumper for each channel.

\section{Battery Pack}

The battery pack is a standard four slot, D-cell holder. It is recommended that four alkaline $\mathrm{D}$ cells be installed (for example, Energizer EN95).

\section{C.4 Cables}

1. Shorting plug/power

a. You may want to install on occasion ( 2 min installed) to prevent the clock/internal memory from resetting.

2. Remote controller and USB cable

a. The attached remote controller allows the user to start, pause, or stop recording.

b. The attached USB cable will enable downloading of files from the unit.

3. Hydrophone cable

4. Blanking cables

a. Always install a blanking connector into the unused ports when using a submersible unit. 
b. For the nonsubmersible unit, installing a blanking connector into the unused ports is recommended but not required.

\section{C.5 Operation}

Always match the cable pins to the connector sockets before installation to avoid damage.

The use of silicone spray lubricant is highly recommended for use on male pins to avoid corrosion.

Always install a blanking connector when using a submersible unit.

1. Install the hydrophone connector(s) to either ports $\mathbf{C H} \mathbf{1}$ or $\mathbf{C H} 2$. If a single hydrophone is used, install a blanking connector on any unused channels.

2. Install the remote connector to the port labeled REMOTE.

3. Power the unit by installing the shorting plug into the port labeled POWER on the unit.

4. Once the shorting plug is installed, the data recorder unit will turn on. If you are using a nonsubmersible USR, you may be able to watch/configure the data recorder.

5. To start recording, use the external remote controller to press the RECORD ( $\bullet$ ) button. The button will begin flashing. Press the PAUSE ( II ) button to start recording.

6. During operation, remove the remote cable from the REMOTE port and replace with a blank cable.

7. To stop recording, remove the blank cable from the REMOTE port. Install the REMOTE cable into the REMOTE port. Press the STOP ( $\mathbf{a})$ button.

To access the memory on the PCM-D50, install the USB cable on the REMOTE cable to any Windows-based computer. The memory will self-install as two separate storage devices, one for internal memory and a second for the Memory Stick Pro-HG Duo memory card (if installed). 
Appendix D

\section{Performance Testing Results}




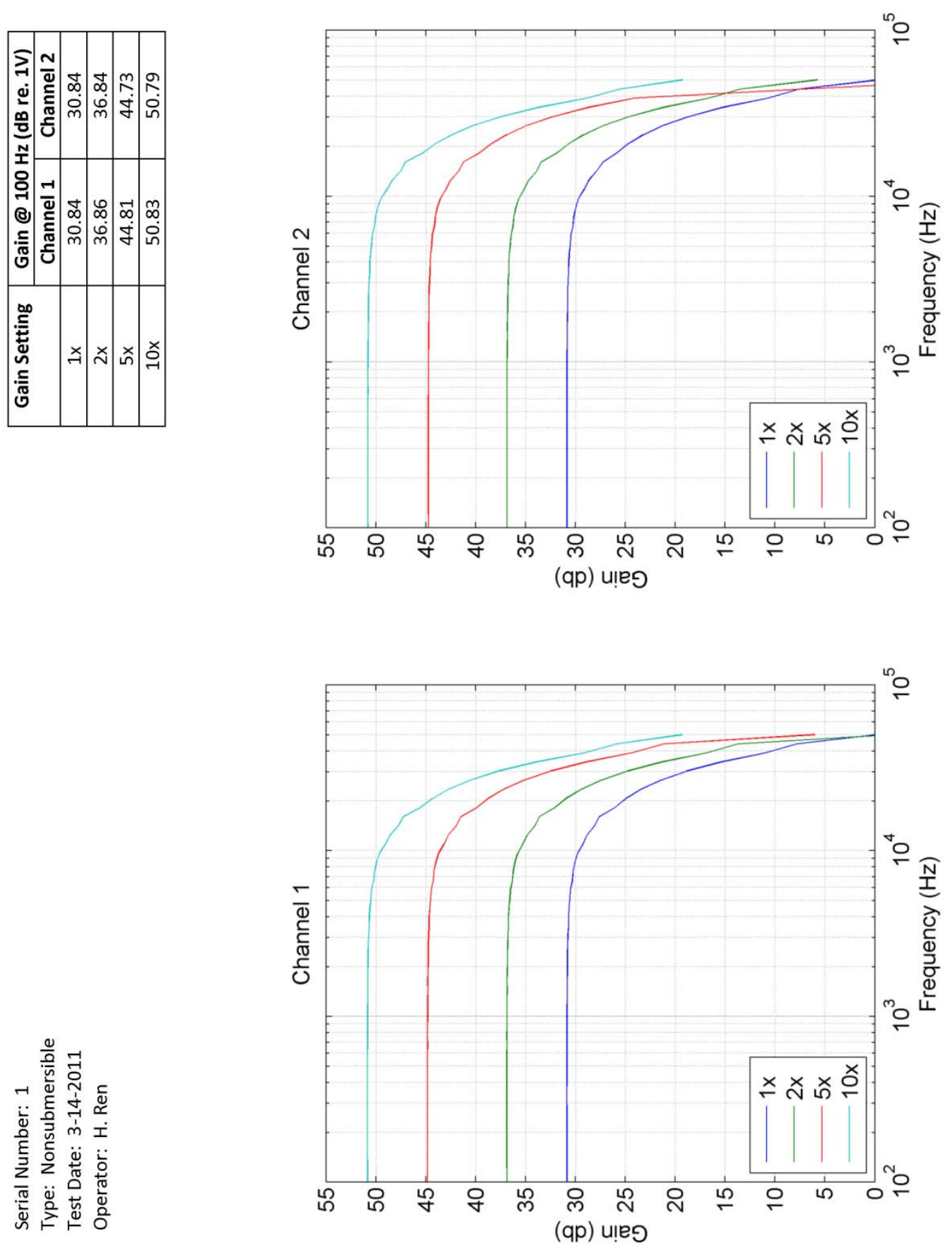

D. 1 

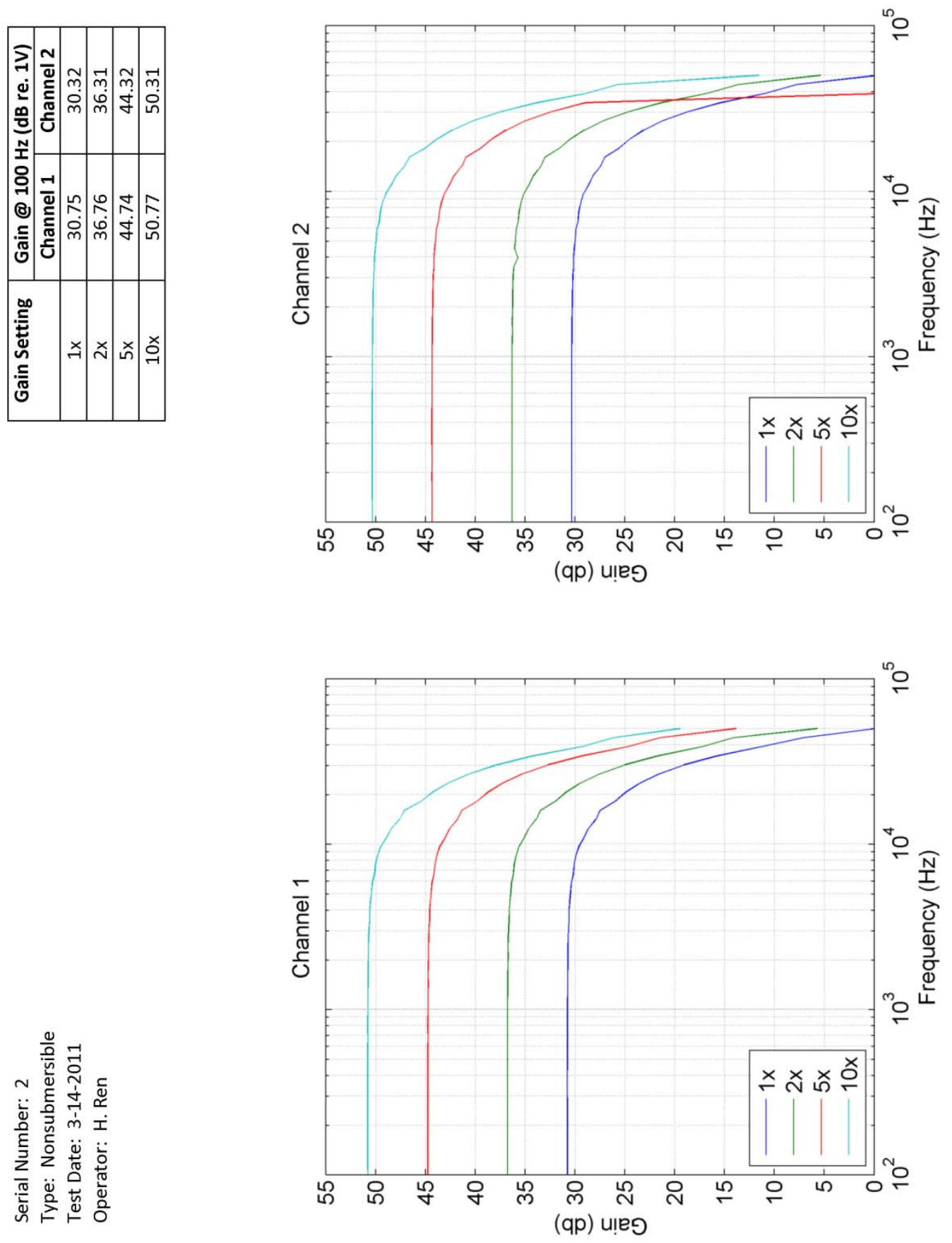

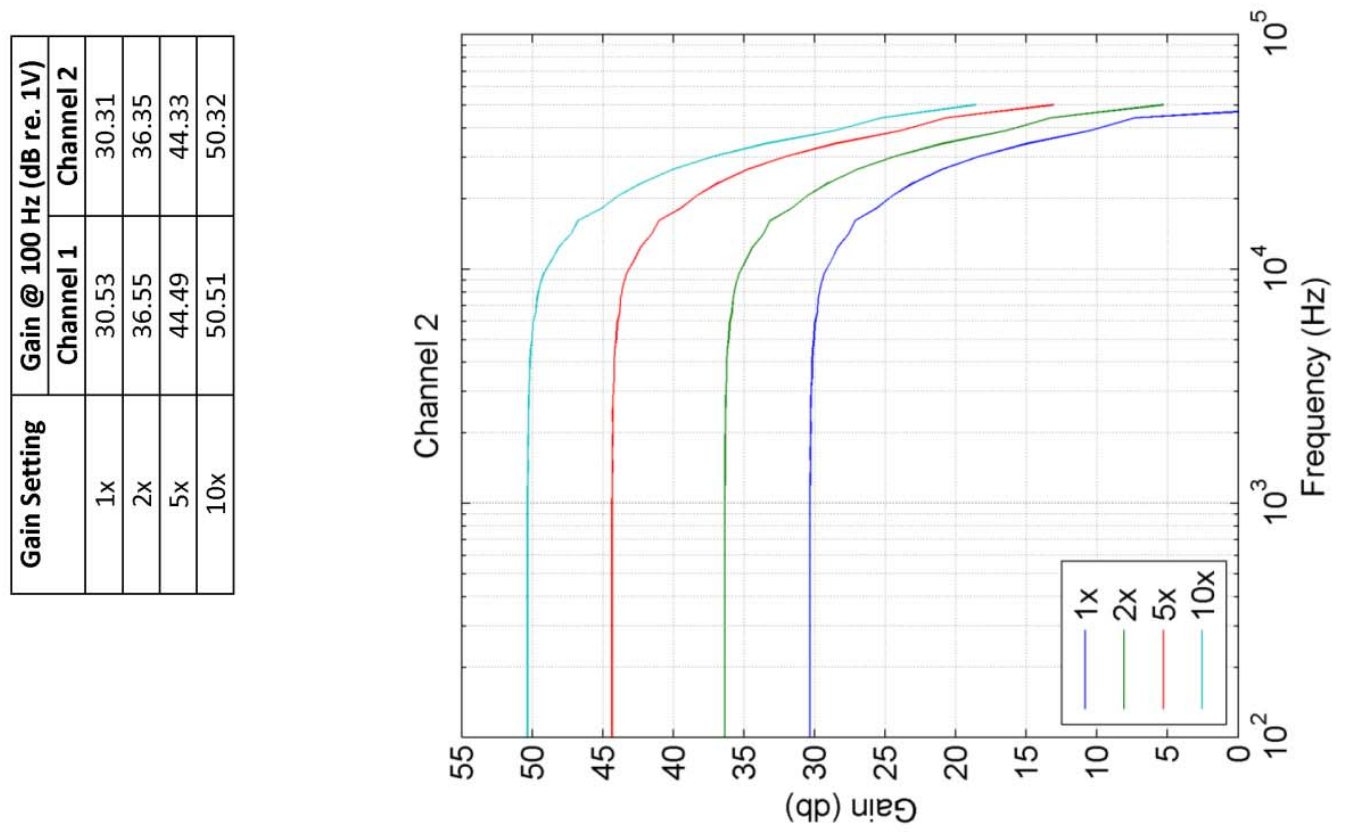

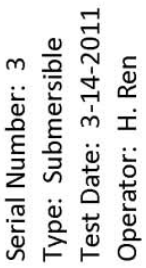

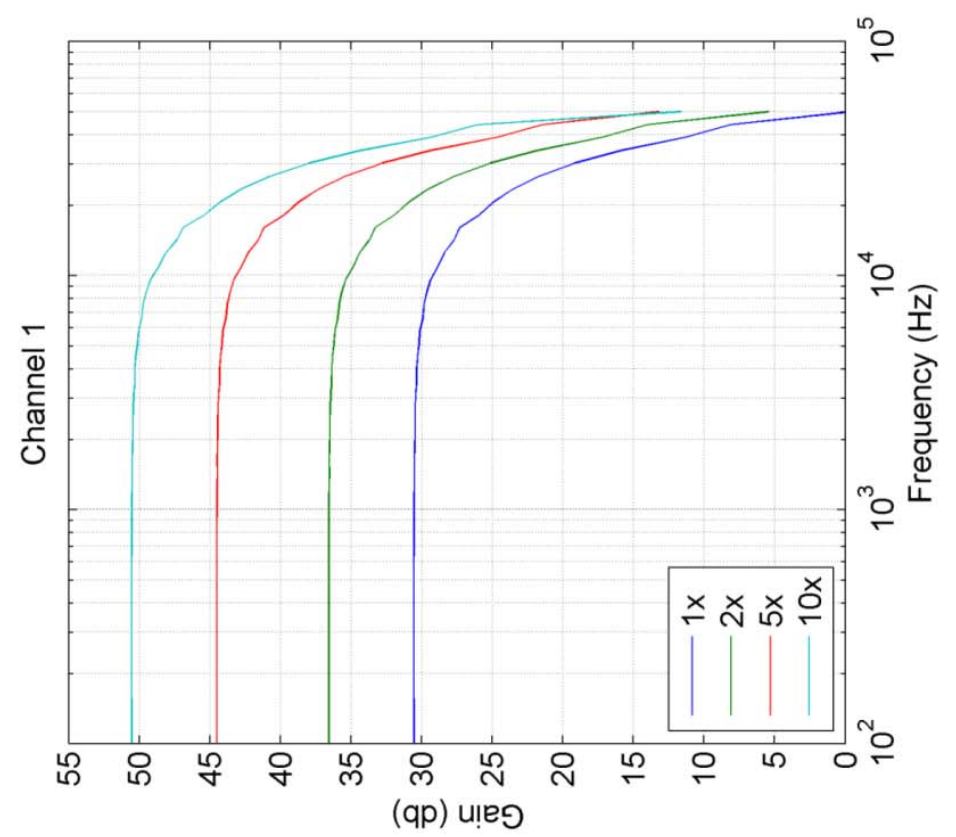



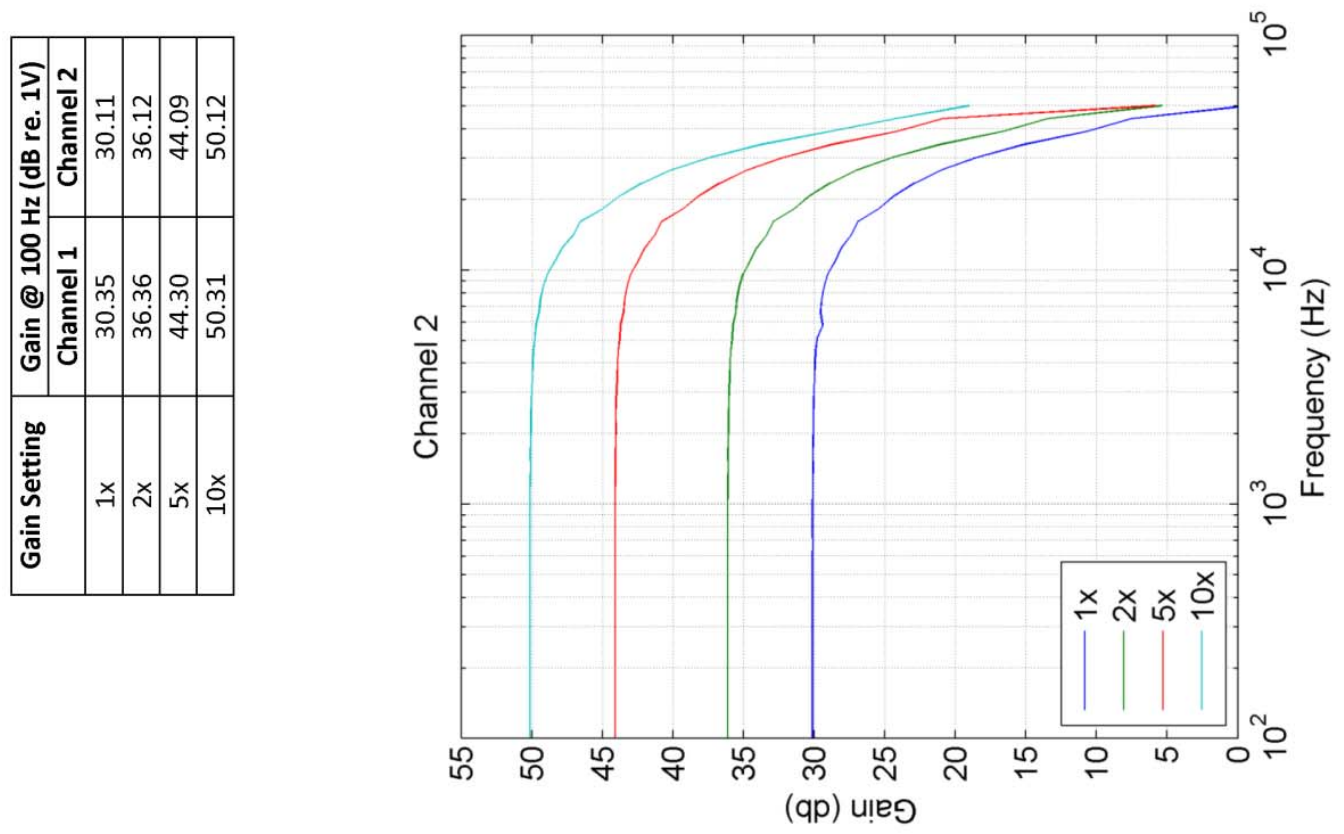

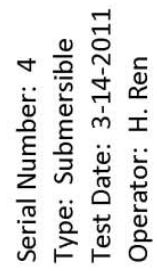

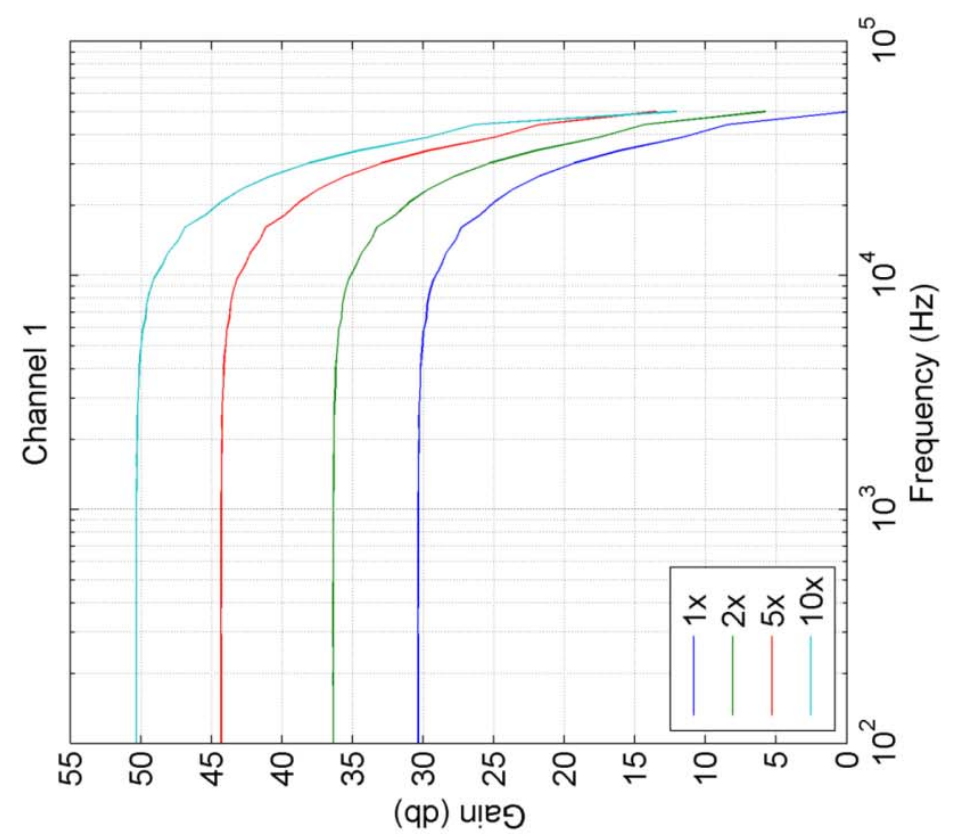





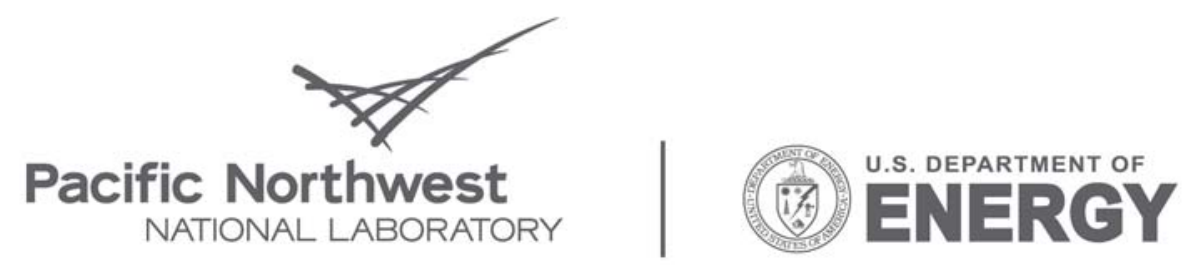

Proudly Operated by Battelle Since 1965

902 Battelle Boulevard

P.O. Box 999

Richland, WA 99352

1-888-375-PNNL (7665)

www.pnl.gov 